\title{
1 A global map of the Zika virus phosphoproteome reveals host-driven regulation of viral
}

\section{2 budding}

3 Inessa Manuelyan ${ }^{1,2}$, Anna M. Schmoker ${ }^{3 \#}$, Boyd L. Yount Jr. ${ }^{4}$, Philip Eisenhauer ${ }^{1}$, Judith I.

4 Keller $^{3}$, Clarissa Gold ${ }^{5}$, Dante Terino ${ }^{1 \neq}$, Christopher M. Ziegler ${ }^{1 @}$, Jeff Alexander ${ }^{6}$, Heather

5 Driscoll $^{7}$, Edward Hutchinson ${ }^{8}$, David Bhella ${ }^{8}$, Christopher D. Syme ${ }^{9}$, Douglas G. Widman ${ }^{10}$,

6 Mark T. Heise ${ }^{10,11}$, Ralph S. Baric ${ }^{4,10}$, Bryan A. Ballif ${ }^{3}$, Jason W. Botten ${ }^{1,12 *}$

$7 \quad{ }^{1}$ Department of Medicine, Division of Immunobiology, Robert Larner, M.D. College of

8 Medicine, University of Vermont, Burlington, VT, USA.

$9{ }^{2}$ Cellular, Molecular, and Biomedical Sciences Graduate Program, University of Vermont,

10 Burlington, VT, USA.

$11{ }^{3}$ Department of Biology, University of Vermont, Burlington, VT, USA

$12{ }^{4}$ Department of Epidemiology, Gillings School of Global Public Health, University of North

13 Carolina, Chapel Hill, NC, USA.

$14{ }^{5}$ Vermont Biomedical Research Network, University of Vermont, Burlington, VT, USA.

$15{ }^{6}$ VLP Therapeutics, Inc., Gaithersburg, MD, USA

$16{ }^{7}$ Vermont Biomedical Research Network, Norwich University, Northfield, VT, USA.

$17{ }^{8}$ MRC-University of Glasgow Centre for Virus Research, University of Glasgow, Glasgow, UK.

$18{ }^{9}$ School of Chemistry, University of Glasgow, Glasgow, UK.

$19{ }^{10}$ Department of Microbiology and Immunology, School of Medicine, University of North

20 Carolina, Chapel Hill, NC, USA.

$21{ }^{11}$ Department of Genetics, School of Medicine, University of North Carolina, Chapel Hill, NC, 22 USA. 
$23 \quad{ }^{12}$ Department of Microbiology and Molecular Genetics, Robert Larner, M.D. College of

24 Medicine, University of Vermont, Burlington, VT, USA.

$25{ }^{\#}$ Current addresses: Department of Cancer Biology, Dana-Farber Cancer Institute, Longwood

26 Center, 360 Longwood Avenue, Boston, MA, USA

$27{ }^{\ddagger}$ Current address: Lineberger Comprehensive Cancer Center, University of North Carolina at

28 Chapel Hill, Chapel Hill, NC, USA.

$29{ }^{\circledR}$ Current address: Imanis Life Sciences, Rochester, MN, USA

30 Current address: Seqirus, Inc. 50 Hampshire Street, Cambridge, MA, USA

31

32 *Correspondence: jbotten@uvm.edu(J.W.B.); Tel.: +1-802-656-9795 (J.W.B.)

33 


\section{Abstract}

35 Flaviviruses are enveloped, positive-strand RNA viruses that cause millions of infections in the

36 human population annually. Although Zika virus (ZIKV) had been detected in humans as early

37 as the 1950s, its reemergence in South America in 2015 resulted in a global health crisis. While

38 flaviviruses encode 10 proteins that can be post-translationally modified by host enzymes, little

39 is known regarding post-translational modifications (PTMs) of the flavivirus proteome. We used

40 mass spectrometry to comprehensively identify host-driven PTMs on the ZIKV proteome. This

41 approach allowed us to identify 43 PTMs across 8 ZIKV proteins, including several that are

42 highly conserved within the Flavivirus genus. Notably, we found two phosphosites on the ZIKV

43 envelope protein that are functionally important for viral propagation and appear to regulate viral

44 budding. Additionally, we discovered 115 host kinases that interacted with ZIKV proteins and

45 determined that Bosutinib, an FDA-approved tyrosine kinase inhibitor that targets ZIKV

46 interacting host kinases, impairs ZIKV growth. Thus, we have defined a high-resolution map of

47 host-driven PTMs on ZIKV proteins as well as cellular interacting kinases, uncovered a novel

48 mechanism of host driven-regulation of ZIKV budding, and identified an FDA-approved

49 inhibitor of ZIKV growth. 


\section{$51 \quad$ Introduction}

52 ZIKV is a mosquito-borne, enveloped, positive-strand RNA virus that encodes three structural

53 proteins (capsid, C; membrane, prM; and envelope glycoprotein, E) and seven nonstructural

54 (NS) proteins (NS1, NS2A, NS2B, NS3, NS4A, NS4B, and NS5; Fig 1A). ZIKV was first

55 discovered in 1947 and confirmed as a human pathogen in 1952 (1). ZIKV belongs to the

56 Flavivirus genus, which has a large disease burden on the human population because of notable

57 members like dengue (DENV), West Nile (WNV), and yellow fever virus (YFV). Though

58 considered a benign disease for most of its known history, ZIKV emerged in South America in

592015 and resulted in a global health crisis that lasted for more than a year and caused over 1.6

60 million infections (2). Most ZIKV infections are asymptomatic, while approximately $20 \%$ of

61 those infected experience mild disease. In rarer cases, detrimental neurological complications

62 arise in the form of Guillain-Barré syndrome as well as fetal microcephaly $(3,4)$. Infants

63 afflicted with microcephaly because of ZIKV infection suffer developmental and health

64 consequences into childhood often with no countermeasures available; those born with severe

65 microcephaly require constant care.

66 Surveys of post-translational modifications (PTMs) on viral proteins have previously

67 been used to understand how viruses affect cells and vice versa. Viral proteins are

68 multifunctional and PTMs are an important host-driven process that can regulate viral protein

69 functionality. Discovery of PTMs can potentially elucidate novel viral protein functions. For

70 example, in human immunodeficiency virus and lymphocytic choriomeningitis virus (LCMV),

71 phosphorylation of viral proteins has been shown to be important in key processes like viral

72 particle budding and regulation of budding of different classes of viral particles (5-8). There have

73 been a small number of flavivirus phosphorylation sites discovered which demonstrate that 
74 phosphorylation of viral proteins can influence the host's innate immune system or evade it,

75 affect functionality of a viral protein, impact viral protein-protein interactions, or regulate the

76 replication of viral RNA (9-13). These important discoveries emerged from studies of NS5

77 proteins of several species of flaviviruses. However, there remains an expansive terrain of other

78 flavivirus proteins. Importantly, identification of novel PTMs and their functional relevance is

79 anticipated to reveal unexplored avenues for pharmacological therapeutics in these diseases. To

80 address this gap in knowledge, herein we performed a large-scale mass spectrometry analysis of

81 the ZIKV proteome to broadly map the PTM landscape of ZIKV. Additionally, we mapped host

82 kinases that interact with the ZIKV proteome and tested whether FDA-approved inhibitors of

83 interacting kinases can be used to inhibit ZIKV growth. Finally, we functionally interrogated a

84 subset of the identified PTMs to determine their importance for ZIKV propagation and, where

85 relevant, mapped the stage of the viral life cycle impacted.

$87 \quad$ Results

88 Discovery of post-translational modifications (PTMs) on the Zika virus proteome

89 A primary goal of this study was to identify host-driven PTMs that occur on ZIKV proteins

90 produced by mammalian cells, either in the setting of cell-free virions or within cells. Where

91 possible, we wished to examine PTMs in the setting of authentic ZIKV infection. At the time of

92 this study, the only suitable antibody available for purification of a ZIKV protein, expressed in

93 the context of an infected cell, was 4G2, which recognizes the ZIKV envelope (E) protein (14).

94 This antibody was used to purify intracellular ZIKV E and its interacting host partners from

95 infected cells (Figs 1B and 1C) or E-decorated, cell-free virions released from these same

96 infected cells (Figs 1B and 1D). Note that immunopurified ZIKV particles contained the 
97 structural proteins E, prM, and C (Fig 1D and Supplementary Information 1). We also isolated

98 cell-free virions from infected mosquito cells via banding on a potassium tartrate density

99 gradient (Fig S1A). To circumvent the lack of antibodies suitable for immunoprecipitation of the

100 remaining ZIKV proteins from cells, we used plasmids to express streptavidin-binding protein

101 (SBP)-tagged ZIKV proteins. This allowed for efficient capture of SBP-tagged viral proteins via

102 magnetic streptavidin beads (Figs 1B, 1E, S2, S3, and S4). To increase the likelihood of

103 detecting phosphorylation events, transfected cells were treated with either $\mathrm{H}_{2} \mathrm{O}_{2}$, Calyculin A, or

104 DMSO to inhibit tyrosine phosphatases, serine/threonine phosphatases, or to act as a control,

105 respectively (Figs 1B, 1E, S2, S3, and S4). Samples derived from immunoprecipitation and

106 affinity purification were subjected to SDS-PAGE to orthogonally separate protein components.

107 Gel lanes were cut into multiple sections, and each piece was subjected to in-gel trypsin

108 digestion. Meanwhile, ultracentrifuged purified virus from mosquito cells (Fig S1B) was

109 digested with trypsin using filter-assisted sample preparation. All resulting tryptic peptides were

110 subjected to liquid chromatography tandem mass spectrometry for identification of PTMs or

111 interacting host proteins as described in the Methods and previously $(8,15)$. Tandem mass

112 spectra for discovered phosphorylation and ubiquitination sites are available in Supplementary

113 Information 2 (spectra for ZIKV E T351 from virions is available in Figs S1C, S1D).

114 We identified 18 phosphorylation sites and 5 ubiquitination sites on ZIKV E (Table 1,

115 Table S1, Figs 2A, and 2B). Two of these phosphorylation sites, Y61 and T351, were discovered

116 in the context of infection (Y61 from infected Vero E6 cells and T351 from mosquito cell-

117 derived ZIKV particles (Fig S1D). T351 was also found on ZIKV E expressed from plasmid in

118 HEK293T cells. The remaining PTMs were identified from plasmid-expressed viral proteins.

119 The locations of Y61, T351, and other PTMs found on ZIKV E are shown in Figs 2A and $2 \mathrm{~B}$. 
120 Y61 is located in Domain II of E, which is the region responsible for dimerization (16). T351 is

121 located in Domain III, which is often a target of neutralizing antibodies (16). PTMs on E were

122 also mapped using electrostatically labeled models (Fig S5). Figure S5A shows one "face" of the

123 ZIKV E dimer as largely positively charged while Figure S5B shows the other largely negatively

124 charged face. In contrast, the border of the E dimer is mostly neutral (Fig S5C). The majority of

125 ZIKV E phosphosites were found on the neutral border of the envelope protein (Fig S5C). The

126 two phosphorylation sites on M, S16 and T18, are positioned in close proximity to one another at

127 a junction of where $\mathrm{E}$ and $\mathrm{M}$ associate (Fig 2C). Interactions between the M S16 and T18

128 phosphorylated residues with $\mathrm{E}$ are hard to resolve, however, because both sites are in flexible

129 regions of $\mathrm{M}$ and are interacting with flexible regions of $\mathrm{E}$ (Fig S6A).

130 We identified 11 phosphorylation sites and one ubiquitination site on NS1 (Table 1,

131 Table S1). Location mapping of PTMs on NS1 revealed that approximately half of the modified

132 amino acid residues were located in the beta-roll or beta ladder domains of NS1 (Fig 2D)

133 important for NS1 intracellular dimerization (17) and host protein interaction (18), respectively.

134 We were unable to successfully express and isolate adequate quantities of NS2A or NS3 to

135 analyze for PTMs (Fig S7). Mass spectrometry revealed a phosphorylated serine at position 71

136 on the NS2B protein (Table 1, Table S1), a small protein known to associate with NS3 to form

137 the ZIKV protease complex (Fig 2E). There were no PTMs found on NS4A despite an

138 abundance of NS4A peptides observed by mass spectrometry. One phosphorylation site was

139 detected on NS4B, though the precise location could not be determined with certainty. Our mass

140 spectrometry data suggest its location to be at either S217, S218, or T219 (Table 1, Table S1).

141 There are currently no models of ZIKV NS4B so we were unable to depict these sites within the

142 protein structure. Last, we discovered four phosphorylation sites on NS5 (Table 1, Table S1). Of 
143 these, two were located in the RNA-dependent RNA polymerase region of NS5 and two in the

144 methyl-transferase region (Fig 2F).

145 To determine how conserved the discovered ZIKV protein PTMs might be with other

146 flaviviruses, we constructed a multiple sequence alignment (MSA) that included viruses

147 spanning the Flavivirus genus and chose flaviviruses known to cause human disease

148 (Supplementary Information 3; virus list also noted in the Methods section). In total, we

149 compared 15 different flaviviruses representing tick- or mosquito-borne viruses, viruses with no

150 known vectors, and those considered emerging pathogens. Amino acid residues were defined as

151 conserved if they were found in at least seven of the 15 flaviviruses in our panel. Of the 43

152 discovered PTMs, 14 met this degree of conservation across the Flavivirus genus and five were

153 conserved across nearly all flavivirus subfamilies, a result that suggests they may be

154 fundamentally important for many species of flaviviruses (Table 1). Notably, four sites were

155 found only in ZIKV isolates (Table 1).

\section{Tyrosine 61 and threonine 351 on the ZIKV E protein are critical for viral growth}

158 We sought to determine whether the PTMs identified were important for viral propagation. We

159 focused on two sites, Y61 and T351 on ZIKV E, because they were found in both infection and

160 plasmid expression settings. Y61 was discovered from infected cells while T351 was found in

161 virions and on plasmid-expressed ZIKV E. Further, these sites represented residues that are

162 either highly conserved in flaviviruses (Y61) or unique to ZIKV (T351) (Table 1; Supplementary

163 Information 3). To evaluate the importance of these sites for viral propagation, we used reverse

164 genetics (19) to recover infectious ZIKV clones encoding mutations at these sites that would 
165 either block or mimic phosphorylation (Fig 3A). We then used these infectious clones in multi-

166 step growth curves to determine how each change impacted viral fitness.

167 ZIKV E Y61 was mutated to a negatively-charged glutamic acid (Y61E) to reflect a

168 permanent state of phosphorylation (i.e. a phosphomimetic) and to a phenylalanine (Y61F) to

169 represent a non-phosphorylatable state. We recovered the non-phosphorylatable infectious clone

170 Y61F but, interestingly, the phosphomimetic clone Y61E appeared to be nonviable as assessed

171 by plaque assay (Fig 3B). Recovery of a Y61E clone was attempted three times without success,

172 despite successful recovery of a WT control clone each time. To account for the possibility that

173 this virus could be propagating but unable to form plaques (and therefore undetectable by plaque

174 assay), we screened for the presence of infectious virus by focus assay (Fig 3C). In parallel, to

175 account for the possibility that the virus was replicating but not with sufficient kinetics to be

176 detectable by focus or plaque assay after the initial recovery passage, we blind-passaged Y61E

177 three times. This approach led to the successful isolation of an infectious clone capable of

178 forming foci beginning at passage 3 (Fig 3C). However, sequencing of this infectious clone at

179 passage 3 revealed that the glutamic acid (Y61E) had mutated to a valine (Y61V), suggesting

180 that there is selection pressure to avoid a permanent negative charge at position 61.

181 To address whether phosphorylation of Y61 influences viral fitness, we performed a

182 multi-step growth curve comparing the phosphomutant clones Y61F and Y61V to a wild-type

183 clone. Interestingly, both the Y61F and Y61V infectious clones grew with accelerated kinetics

184 and produced higher quantities of infectious virus compared to the wild-type clone (Fig 3D;

185 Y61F p =0.006).

186 ZIKV E T351 was mutated to an aspartic acid (T351D) to mimic a state of

187 phosphorylation or an alanine (T351A) to act as a non-phosphorylatable mutant. Infectious 
clones of each mutant were successfully recovered (Fig 3B) and multi-step growth curves were

performed. There was no difference between the growth of the phosphomimetic T351D mutant

191 phosphorylatable mutant was impaired compared to WT virus or the T351D mutant (Fig 3E; $p=$

192 0.0009). After 72 hours, the titers for the T351D and the wild-type infectious clones decreased

193 more rapidly compared to T351A. This could be due to the fact that the wild-type and T351D

194 clones caused more cytopathic effect at this time point and therefore the cells could not support

195 further rounds of infection.

196 In summary, both the Y61 and T351 sites appear important for viral propagation. Our

197 results suggest that blocking phosphorylation at Y61 enhances viral growth while blocking

198 phosphorylation at T351A impairs it.

\section{Y61 and T351 on ZIKV E are required for efficient Zika virus budding}

201 To determine the life cycle stage impacted by ZIKV E Y61 or T351, we next tested how a

202 phosphomimetic or non-phosphorylatable mutation at each site would impact viral budding. To

203 do so, we used a virus-like particle (VLP) assay that features a single plasmid that expresses

204 ZIKV prM and E. Once expressed, these two proteins form ZIKV VLPs that bud from cells and 205 can be detected in supernatant (20). The plasmid was mutated at ZIKV E Y61 to Y61E or Y61F

206 and at T351 to T351A or T351D. Compared to the wild-type control, VLP budding efficiency

207 was decreased when T351 was mutated to alanine (T351A) but not aspartic acid (T351D) (Fig

$2083 \mathrm{~F} ; \mathrm{p}=0.04)$. Mutation of Y61 to $\mathrm{F}$ also reduced budding efficiency (Fig 3F, $\mathrm{p}=0.006$ ).

209 Interestingly, we were unable to express ZIKV E protein when Y61 was mutated to Y61E

210 despite performing two bacterial transformations and evaluating several clones from each 
211 transformation. This result, combined with our inability to isolate genetically stable Y61E

212 infectious clones (Fig 3C), suggests that constitutive phosphorylation at Y61 is not favorable

213 either for protein expression or viral growth. Taken together, our findings suggest that both the

214 Y61 and T351 phosphosites are required for efficient ZIKV budding.

216 Host protein kinases interact with the Zika virus proteome

217 We next wished to determine the host kinases that associate with ZIKV proteins. The

218 immunoprecipitation and affinity purification performed in Figs 1C, 1D, 1E, S2, S3, and S4 not

219 only captured ZIKV proteins, but also their host cellular protein partners. Thus, we were able to

220 identify host kinases that interacted with ZIKV C, M, E, NS1, NS2B, NS4A, and NS4B. We

221 used Scansite 4.0 software to predict kinases that might phosphorylate ZIKV proteins at the sites

222 of phosphorylation identified in this study (Table 1). Intriguingly, some of the predicted kinases

223 were interacting partners of ZIKV proteins (Table 1, highlighted in purple). Other predicted

224 kinases, although not found by mass spectrometry to be interacting partners, either have shared

225 homology with or are found in the same cascades as interacting kinases (Table 1, highlighted in

226 blue). In total, we found 115 cellular kinases that interacted with ZIKV proteins (Table S2).

227 Figure 4A shows the top 10 most abundant kinases, determined by number of tryptic peptides

228 detected from a given viral protein during mass spectrometry. Most interacting kinases were

229 found to interact with two or more viral proteins. Five kinases interacted with 4 ZIKV proteins

230 found to have PTMs. These kinases were AURKB, CAMK2B, CDK2, PLK1, UCK2 (Aurora

231 Kinase B, Calcium/Calmodulin Dependent Protein Kinase II Beta, Cyclin-dependent kinase 2,

232 polo-like kinase 1, Uridine-Cytidine Kinase 2, respectively; Fig 4A, black circles). AURKB was 
233 predicted by Scansite 4.0 to interact with ZIKV M and E, CAMK2B was predicted to interact

234 with M, and PLK1 was predicted to interact with E, NS1, NS4B, and NS5 (Table 1, Table S2).

$236 \quad$ Inhibition of host cell kinases by Bosutinib impairs Zika virus growth

237 Considering that there are no FDA approved treatments for ZIKV, we next tested whether

238 selected FDA-approved kinase inhibitors might be effective in restricting ZIKV growth. We

239 focused on a panel of tyrosine and serine/threonine inhibitors to see if they could impact ZIKV

240 growth. At $10 \mu \mathrm{M}$, the tyrosine kinase inhibitors Bosutinib and Defactinib both reduced ZIKV

241 titers (Fig 4B; $\mathrm{p}=0.03, \mathrm{p}=0.02$, respectively) while Sunitinib and Imatinib did not (Fig 4B; $\mathrm{p}=$

$2420.17, \mathrm{p}=0.35$, respectively). To determine the $\mathrm{IC}_{50}$ of each drug, we constructed concentration-

243 response curves. To account for drug cytotoxicity, we performed simultaneous MTT assays on

244 cells that had been treated with each kinase inhibitor at the equivalent concentrations. Although

245 Defactinib inhibition of ZIKV infectious virus production reached levels as high as $86 \%$, at the

246 same concentration of drug, cell toxicity measured 73\% (Fig 4C). At Defactinib's IC 50 of 4.5

$247 \mu \mathrm{M}$, cell toxicity was approximately $46 \%$. The fitted curve of inhibition and cell toxicity closely

248 followed each other, suggesting that most of the viral inhibition may have been due to nonviable

249 cells. After determining the $\mathrm{CC}_{50}$ of Defactinib to be $7.53 \mu \mathrm{M}$, we calculated the selectivity index

250 for Defactinib to be 1.7. The $\mathrm{IC}_{50}$ of Bosutinib was $5.5 \mu \mathrm{M}$. In this case, at the same doses of

251 drug, cell toxicity was approximately 17\%. At higher concentrations, Bosutinib completely

252 inhibited viral growth while cell toxicity remained at approximately $30 \%$ (Fig 4D). Given

253 Bosutinib's IC50 and $\mathrm{CC}_{50}(17.43 \mu \mathrm{M})$, we calculated the selectivity index to be 3.14 . These

254 results suggest that Bosutinib impairs ZIKV growth and that host cell kinases may be tractable

255 antivirals for ZIKV. 


\section{Discussion}

258 Little is known regarding the diversity of host-driven PTMs that occur on flavivirus proteins or

259 how such modifications regulate the functionality of these proteins. We addressed this deficiency

260 by providing the first comprehensive map of phosphorylation and ubiquitination sites found on a

261 flavivirus proteome. A major finding was that selected phosphorylation sites on the ZIKV E

262 protein appear critical for ZIKV propagation, likely at the stage of viral assembly and release.

263 We also identified a network of host kinases that interact with ZIKV proteins, with many of

264 these kinases predicted to target the newly identified phosphosites. Notably, our data suggest that

265 inhibition of host kinases may be an effective approach to restrict ZIKV growth.

266 Flavivirus budding occurs at the endoplasmic reticulum and is largely driven by prM and

267 E. This pair of structural proteins together induce curvature in the ER membrane leading to the

268 formation of spherical budded virions that contain the encapsidated viral genome (21). We show

269 that the ZIKV envelope glycoprotein (ZIKV E) has at least two phosphosites, Y61 and T351,

270 which are involved in the budding stage (Fig 3F). Intriguingly, while mutation of these sites to a

271 non-phosphorylatable residue blocks efficient budding in a VLP assay (Fig 3F), infectious clones

272 of ZIKV encoding these same mutations have opposing effects - Y61F leads to enhanced

273 infectious virus production while T351A does the opposite (Figs 3D-E). To our knowledge,

274 phosphorylation of a flavivirus protein has not been implicated in the budding process. Thus, our

275 data suggests that phosphorylation of E may play a regulatory role in ZIKV budding. Moreover,

276 considering the conservation of Y61 in other pathogenic flaviviruses (Table 1, Supplementary

277 Information 3), this PTM could be fundamentally important for flavivirus budding. Additionally,

278 two ubiquitination sites on ZIKV E were recently shown to be required for viral entry and 
replication (22). Notably, one of these ubiquitination sites, K281, was detected in the present

280 study (Table 1, Table S1).

Phosphosite Y61 is found in domain II of ZIKV E, the domain responsible for ZIKV E

282 dimerization (16). The inability of the phosphomimetic Y61E infectious clone to efficiently grow

283 over the first two passages following reverse genetics rescue coupled with its conversion at this

284 residue from a glutamic acid to valine by passage 3 (Fig 3C, 3D) suggest that the negatively

285 charged amino acid is not favorable. Indeed, there may be pressure at position 61 to be either a

286 non-charged or hydrophobic amino acid. A zoomed-in view of the ZIKV model reveals that Y61

287 is near an asparagine (N207) and glutamic acid (E262) (Fig S6B). In the absence of

288 phosphorylation, it is possible that the N207 and E262 residues are interacting. A large

289 phosphate group on Y61 would possibly disrupt this interaction and perhaps repel the negative

290 charge on E262, providing a possible explanation for why a non-charged state is optimal at this

291 this position. This preference is further supported by the fact that we readily rescued the

292 nonphosphorylatable mutant, Y61F, which has a hydrophobic, non-charged phenylalanine at

293 position 61.

294 The hydrophobic amino acid changes ( $\mathrm{Y}$ to $\mathrm{F}$ or $\mathrm{V}$ ) at position 61 resulted in ZIKV

295 infectious clones that outperformed wild type ZIKV in reaching peak titers (Fig 3D). We

296 interpret this finding in several ways. First, phosphorylation of ZIKV E at Y61 is either not

297 favorable to the virus or is beneficial at very specific time point(s) in the ZIKV life cycle. If the

298 latter scenario is at work, our growth curve data may not be sufficient to resolve this idea

299 because the infectious clones employed contained static mutations at this position. The

300 negatively-charged phosphosite may be important in aiding a specific purpose, such as

301 encouraging a conformational change for a period and then returning to an unphosphorylated 
state. When mutated to Y61E, ZIKV E no longer expressed from a plasmid, suggesting that the ZIKV envelope protein containing a negatively-charged glutamic acid at this position is too

304 unstable for expression or may be quickly marked for degradation. Interestingly, the Y61 site is

305 highly conserved among flaviviruses. A multiple sequence alignment (Supplementary Information 3) shows that flaviviruses such as WNV, YFV, Japanese encephalitis virus (JEV),

307 and Saint Louis encephalitis virus (SLEV) also contain a tyrosine at this position, suggesting that maintaining control over the charge of this tyrosine likely benefits these flaviviruses. DENV contains an isoleucine at this position and more distantly related flaviviruses contain a leucine,

310 both of which share properties with tyrosine and phenylalanine in that they are also non-charged, 311 hydrophobic amino acids.

313 peak infectious titers is the possibility that the phosphorylation of Y61 drives the production of

314 defective interfering particles (DIPs), but not infectious particles. Under this scenario, blocking

315 phosphorylation at Y61 would dampen the output of DIPs. The decrease in DIPs would result in

316 a greater number of permissive cells available to the infectious particles produced (i.e. more

317 replication space in the cell culture dish for infectious virions would equate to a greater

318 infectious virus output). There is a precedent for this hypothesis in our previous studies of the

319 mammarenavirus lymphocytic choriomeningitis virus (LCMV) $(6,23)$. In the case of LCMV,

320 phosphorylation of Y88 on the viral matrix protein - the protein that drives viral budding -

321 uniquely promotes DIP production. Y88 sits within the PPXY late domain on the LCMV matrix

322 protein. Mutation of Y88 to a nonphosphorylatable amino acid (i.e. Y88F) blocked the

323 production of DIPs and led to increased kinetics of infectious virus production. Notably, similar

324 to Y61, mutation of Y88 to a nonphosphorylatable amino acid resulted in impaired VLP 
production (Fig 3F). This could suggest that the impairment in budding observed in both LCMV Y88F and ZIKV Y61F is reflective of DI particle budding, but not infectious particles. phosphorylation could also be due to the blockage of conformational changes of ZIKV E necessary for virus particle maturation. Flavivirus virion populations are composed of a mixture of mature and immature virus particles. For ZIKV particles to mature, the host protease furin has to cleave prM in the trans-Golgi network. This cleavage is contingent on a ZIKV E conformational change that is triggered by the acidic environment of the trans-Golgi network, exposing the cleavage site on prM (24). It is possible that phosphorylation of Y61 or the

334 presence of a negatively-charged amino acid at position 61 would allosterically block this

335 conformational change and shift the population of mature particles to immature particles.

336 Conversely, a lack of a negative charge at this site (i.e. Y61F or Y61V in Fig 3) may promote the 337 necessary conformational changes to occur at a higher rate, shifting the population of viral 338 particles to mature, infectious particles. cells. T351 sits within Domain III of ZIKV E, which contains motifs for cellular receptor binding

341 and is often the target of neutralizing antibodies (16). A negative charge at this position, either

342 from a phosphorylated threonine or an aspartic acid substitution, was optimal for growth (Fig

343 3E). Similarly, a negatively charged aspartic acid in the budding assay resulted in the

344 maintenance of virus-like particle budding. Conversely, mutation to an alanine, the

345 nonphosphorylatable mutant, resulted in a strong reduction in virus-like particle budding (Fig

$3463 \mathrm{~F}$ ), suggesting that host-driven phosphorylation of T351 promotes ZIKV budding. Intriguingly,

347 phosphorylation of T351 was discovered both on ZIKV E isolated from human cells as well on 
348 virions derived from mosquito cells, suggesting that not only is phosphorylation of T351

349 important in the host, but that it may also play a role in the virus vector. Future studies could

350 focus on confirming the functional importance of T351 and other discovered phosphosites, such

351 as Y61, in mosquito cells, as well as evaluating whether phosphomutant viruses from mosquito

352 cells impact entry or infectivity in human cells. Because there may be differences in human and

353 arthropod kinomes, it is possible that the ZIKV phosphoproteome in vector cells would diverge

354 from our dataset in mammalian cells. Additionally, it may be that optimal viral fitness requires

355 different patterns of regulatory phosphorylation in the cells of mammalian and arthropod hosts.

356 Therefore, it would be informational to map the phosphoproteome of ZIKV in mosquito cells for

357 comparison with this dataset as well as for comparison of the roles of phosphorylation in both

358 cell types.

Previous studies have shown that host-driven phosphorylation of the flavivirus NS5

360 protein is critical for the flavivirus viral life cycle. For example, phosphorylation of YFV NS5 at

361 a highly conserved site (S56) is required for YFV to evade the cap-dependent innate immune

362 response in the host cell (9). Blocking the phosphorylation of another conserved flavivirus

363 residue, T449 on DENV NS5, results in a nonfunctional protein (25). Other key studies linked

364 phosphorylation of NS5 or Hepatitis C virus NS5A to important functions such as its interaction

365 with NS3 $(10,26)$, localization during different stages of infection (26), and viral particle

366 assembly and viral replication $(11,27)$. In some instances, phosphorylation of NS5 was detected

367 but not the specific residues driving the observed phenotype $(10,26)$. The highly conserved NS5

368 phosphosites identified in our study may be responsible for driving these important functions

369 (Table 1). Indeed, we have uncovered several highly conserved phosphosites in the ZIKV 
370 proteome that may help guide the discovery of new functions for these viral proteins or the

371 mechanisms by which these functions are regulated.

372 Our mass spectrometry analysis revealed 115 host kinases (Table S2) that interacted with

373 one or more of the 8 ZIKV proteins probed, which raises the possibility that some subset of these

374 interacting kinases may be responsible for phosphorylation of these viral proteins. Treating cells

375 after infection with Bosutinib, an FDA-approved tyrosine kinase inhibitor, inhibited ZIKV

376 growth (Fig 4B-C). Indeed, a recent study by Valencia et al. confirmed our findings in the setting

377 of ZIKV infection in BHK-21 cells (28). One possibility is that Bosutinib is acting on CDK2, a

378 kinase found to interact with 5 ZIKV proteins (4 of which were phosphoproteins) (Fig 4A).

379 Scansite 4.0 did not predict that CDK2 would phosphorylate any of the ZIKV phosphoproteins,

380 however, host kinases can phosphorylate viral proteins at non-canonical motifs (29). Thus,

381 although not predicted, it is possible that CDK2 phosphorylates ZIKV proteins. It is also

382 important to consider that the concentration at which kinase inhibitors are administered will

383 influence their specificity; further studies are needed to identify the exact mechanism by which

384 Bosutinib decreases viral titers. Additional studies using molecules related to Bosutinib may

385 improve efficacy and specificity for blocking specific kinases. Collectively, these data imply that

386 blocking phosphorylation by host kinases is a potential antiviral strategy.

387 Several interacting kinases (ATM, ATR, and mTOR) discovered in our study were the

388 targets of early drug screens against ZIKV. Specifically, Cherry et al. used inhibitors VE-822

389 and WAY-600 to robustly block ZIKV infection (30). Intriguingly, VE-822 targets ATM and

390 ATR, which we found to be interacting partners of M (ATM, ATR) or E (ATM) (note that ATM

391 is predicted to phosphorylate S16 on ZIKV M; Table 1). WAY-600 targets mTOR, which we

392 found to be an interacting partner of phosphoproteins $\mathrm{M}$ and $\mathrm{E}$ as well as NS4A (Fig 4A). 
393 Interestingly, mTOR was the most abundant kinase found to interact with any of the ZIKV

394 proteins (Table S2). Its importance in ZIKV was found early on when it was discovered that

395 ZIKV proteins can suppress the Akt-mTOR pathway, leading to impairment of neurogenesis and

396 upregulation of autophagy, which is beneficial for ZIKV during replication $(31,32)$. Another

397 study found an overall downregulation of the AKT/mTOR pathway during ZIKV infection (33).

398 Due to ZIKV M associating with high levels of mTOR (see peptide counts in Table S2), we

399 theorize that ZIKV M could be acting as a sink for mTOR, providing an explanation for why the

400 pathway is downregulated and there is less phosphorylation of mTOR targets observed during

$401 \quad$ ZIKV infection (33).

402 In summary, we have detailed a high-resolution map of host-driven PTMs on ZIKV

403 proteins, uncovered a novel mechanism by which ZIKV budding may be regulated, and

404 identified an FDA-approved drug that could be repurposed for the treatment of ZIKV infection.

405 The dataset described here will be useful to the field for the discovery of novel ZIKV protein

406 functions and the mechanisms by which these functions are regulated. Our work further suggests

407 that targeting host kinases may be an effective antiviral strategy and provides potential targets.

408

409 Materials and Methods

410 Cells and viruses

411 HEK 293T/17 cells (CRL-11268), referred to as HEK293T throughout, and A549 cells (CCL-

412 185) were procured from the American Type Culture Collection (ATCC, Manassas, VA). Vero

413 E6 cells were kindly given by J. L. Whitton (The Scripps Research Institute, La Jolla, CA).

414 HEK293T cells were maintained in Dulbecco's modified Eagle medium (DMEM) containing

415 10\% fetal bovine serum (FBS), 1\% penicillin-streptomycin, 1\% HEPES buffer solution, 1\% 
416 MEM nonessential amino acid solution, and 1\% GlutaMAX, from Thermo Fisher Scientific

417 (Waltham, MA). A549 cells were maintained in DMEM-F12 (Thermo Fisher) containing 10\%

418 FBS and 1\% penicillin-streptomycin. Vero E6 cells were maintained in DMEM containing 10\%

419 FBS, 1\% penicillin-streptomycin, and 1\% HEPES buffer solution. Cell lines described above

420 were incubated at $37^{\circ} \mathrm{C}$ with $5 \% \mathrm{CO}_{2}$. Aedes albopictus mosquito cells (C6/36; a kind gift of

421 Prof Alain Kohl, MRC-University of Glasgow Centre for Virus Research) were maintained in

422 Leibovitz's L15 media (Gibco) containing 10\% FBS (Gibco), 10\% triptose phosphate broth

423 (Gibco), and 1\% pen/strep (Gibco) and incubated at $28^{\circ} \mathrm{C}$. ZIKV strain BeH819015, a Brazilian

424 isolate (GenBank: KU365778.1), was generously provided by the Baric Lab (University of North

425 Carolina, Chapel Hill, North Carolina, USA) (19). The Zika virus strain used to infect mosquito

426 cells was ZIKV/H.sapiens/Brazil/PE243/2015 (Recife, Brazil) (34). Working stocks of infectious

427 ZIKV, including recombinant ZIKV clones generated via reverse genetics (see below for details

428 on recovery), were grown on Vero E6 cells and titered by standard plaque assay.

\section{$429 \quad$ Plasmids}

430 Several plasmids were used for expression of ZIKV proteins. The nucleotide sequences of ZIKV

431 ORFs used in this study were derived from ZIKV strain H/PF/2013 (NCBI gene identifier

432 number AHZ13508). The Heise lab (University of North Carolina, Chapel Hill, North Carolina,

433 USA) provided their pOME plasmid-based library that permits expression of each ZIKV ORF

434 containing a C-terminal 3XFLAG tag (35). To enable streptavidin-based affinity purification of

435 ZIKV proteins, the ZIKV C, E, M, NS1, NS2B, and NS4A ORFs encoded in the pOME plasmids

436 were subcloned into our modified pCAGGS expression vector $(36,37)$ such that they would

437 encode a C-terminal streptavidin binding peptide (SBP)

438 (MDEKTTGWRGGHVVEGLAGELEQLRARLEHHPQGQREP) in place of the 3XFLAG tag. 
Each ZIKV ORF was fused to the SBP tag through an 18 base pair linker. The nucleotide

440 sequence of the ZIKV genes was amplified by PCR from the pOME vectors with forward

441 primers that contained a 5' overhang containing a Gateway AttB1 site and a Kozak sequence and

442 reverse primers containing an overhang with the linker sequence (all primers used are listed in

443 Supplementary Information 4). The SBP tag was amplified from a previously generated in-house

444 plasmid via PCR using the forward primer SBP (5'-

445 GCAGCTGGAGGTGGAGGTATGGACGAAAAAACCACCGGT-3'), which has a 5' overhang

446 containing the linker sequence, and the reverse primer SBP (5'-

447 ACCACTTTGTACAAGAAAGCTGGGTCTTACGGTTCACGCTGACCCTGCGG-3’), which

448 contains a 3' overhang with a stop codon preceding an AttB2 sequence. The two PCR products

449 (each respective amplified ZIKV gene and the amplified SBP tag) were fused by PCR using the

450 appropriate ZIKV gene forward primer and the SBP reverse primer. The resulting cassette was

451 subcloned into the modified pCAGGS vector using the Gateway cloning system (Invitrogen)

452 following the manufacturer's instructions. pOME plasmids encoding ZIKV NS2A, NS3, NS4B,

453 or NS5, each with the same C-terminal linker and SBP tag as described directly above, were

454 generated by GenScript Biotech Corporation (Piscataway, NJ, USA) but were maintained in the

455 original pOME vector. Plasmids for the ZIKV reverse genetics system were kindly provide by

456 the Baric Lab as described in Widman et al. (19). The plasmid from the Baric system which

457 contained the ZIKV E gene was modified by GenScript to include the Y61F, Y61E, T351A, and

458 T351D mutations. The plasmid used for the virus-like-particle budding assay, which encodes the

459 ZIKV prM and E genes, is described here (20) and was generously provided by Emergent

460 BioSolutions, Inc. This plasmid was also modified by GenScript to include the include the Y61F,

461 Y61E, T351A, and T351D mutations. All plasmid sequences were verified by DNA sequencing. 


\section{Identification of post-translational modifications of ZIKV proteins by mass spectrometry}

463 To identify phosphorylation sites on ZIKV proteins via mass spectrometry, three general

464 approaches were taken. In the first approach, to purify ZIKV E, Vero E6 cells were infected with

465 ZIKV at an MOI of 0.1 and 72 hours later cells were collected, and lysed in Triton buffer

466 consisting of $1 \%$ Triton X-100, $0.5 \%$ NP40, $140 \mathrm{mM} \mathrm{NaCl}$, and 25mM Tris-HCl containing a

467 protease inhibitor cocktail (04693159001, Roche Applied Science, Indianapolis, IN) as well as

468 PhosStop phosphatase inhibitor cocktail (04906837001, Roche Applied Science). The resulting

469 protein lysate was incubated with anti-ZIKV E $4 \mathrm{G} 2$ antibody at $4^{\circ} \mathrm{C}$, overnight. The next day,

470 magnetic Protein G Dynabeads (ThermoFisher Scientific, Waltham, MA) were added to the

471 lysate-antibody mixture and incubated at $4^{\circ} \mathrm{C}$, rotating for at least 4 hours (but not more than 8

$472 \mathrm{hr}$ ). Beads were then magnetically isolated, gently washed 3 times in Triton buffer, magnetically

473 isolated for a final time and then boiled in Laemmli buffer $(62.5 \mathrm{mM}$ Tris-HCl, $10 \%$ glycerol,

$4742 \%$ sodium dodecyl sulfate and $0.01 \%$ bromophenol blue (B392, Fisher Scientific, Pittsburgh,

475 PA) for 5 minutes to release antibody, ZIKV E protein, and associated host or viral protein

476 partners. Similarly, ZIKV virions were immunopurified from infected Vero E6 cell media 96

477 hours post-infection using Dynabeads coated with anti-ZIKV E 4G2 antibody then lysed using

478 10X Triton buffer containing the same protease and phosphatase inhibitor cocktails described

479 directly above.

480 To purify ZIKV proteins expressed from plasmid, our second approach was to transfect

481 HEK293T cells with modified pCAGGS plasmid expressing ZIKV C, M, E, NS1, NS2B, NS4A,

482 NS4B, or NS5 proteins with a C-terminal SBP tag in each case. $5 \times 10^{5}$ cells per well in 6-well

483 plates were transfected with $2 \mu \mathrm{g}$ of plasmid using $8 \mu \mathrm{g}$ of polyethylenimine (23966,

484 Polysciences, Inc., Warrington, PA), which was reconstituted at $1 \mathrm{mg} / \mathrm{mL}$. Two days later, 
transfected cells were treated either with DMSO (D2650, Sigma-Aldrich. Saint Louis, MO),

$486 \mathrm{H}_{2} \mathrm{O}_{2}$, (Thermo Fisher) or Calyculin A (Cell Signaling Technology, Danver, MA) for 20 minutes.

487 Cells were collected and lysed with Triton buffer (same formulation described above) and then

488 subjected to affinity purification using magnetic MyOne Streptavidin T1 beads (65601, Thermo

489 Fisher Scientific) according to the manufacturer's instructions. Briefly, magnetic beads were

490 washed in buffer several times, added to protein lysates from transfected cells, and then rotated

491 overnight at $4^{\circ} \mathrm{C}$. The next day, the beads were magnetically isolated and washed several times

492 with lysis buffer containing protease and phosphatase inhibitors and then boiled in Laemmli

493 buffer for 5 minutes to release SBP-tagged ZIKV proteins from the streptavidin beads.

495 4-20\% Tris-Glycine polyacrylamide gels (EC60255, Invitrogen). To visualize protein bands for

496 excising and mass spectrometry processing, gels were stained with Coomassie (40\% methanol,

$49720 \%$ acetic acid, and 0.1\% Brilliant Blue R (B7920, Sigma-Aldrich)). Gels were destained with a 498 solution of $30 \%$ methanol and $10 \%$ acetic acid and imaged using a Canon Canoscan $8800 \mathrm{~F}$

499 scanner. Sample lanes were cut into a series of gel pieces containing prominent protein bands or

500 band groups. After excision, gel pieces were further cut into $1 \mathrm{~mm}$ cubes and processed.

501 Chemicals used for processing were purchased from Thermo Fisher Scientific. Gel pieces were

502 rinsed with HPLC-grade water and then incubated with destain solution (50 $\mathrm{mM}$ ammonium

503 bicarbonate and $50 \%$ acetonitrile) for 30 minutes at $37^{\circ} \mathrm{C}$. Destain was removed and gel pieces

504 were dehydrated by incubating twice with $100 \%$ acetonitrile for 5 minutes. The gel pieces were

505 reduced with $25 \mathrm{mM}$ dithiothreitol in $50 \mathrm{mM}$ ammonium bicarbonate for 30 minutes at $55^{\circ} \mathrm{C}$.

506 After cooling, gel pieces were dehydrated with 100\% acetonitrile for 5 minutes and then

507 alkylated with $10 \mathrm{mM}$ iodoacetamide in $50 \mathrm{mM}$ ammonium biocarbonate for 45 minutes at room 
temperature, while protected from light. Gel pieces were washed twice in destain solution for 5 minutes, dehydrated with $100 \%$ acetonitrile, then rehydrated with water for 10 minutes. Gel pieces were further dehydrated with two 5-minute incubations in 100\% acetonitrile. All liquid

511 was removed and gel pieces were left to incubate at room temperature to evaporate trace

512 acetonitrile. Gel pieces were rehydrated with a solution of $12.5 \mathrm{ng} / \mu \mathrm{L}$ sequencing-grade,

513 modified trypsin (V5111, Promega) in $50 \mathrm{mM}$ ammonium bicarbonate on ice for 30 minutes,

514 before digesting overnight at $37^{\circ} \mathrm{C}$. Peptides were extracted with a solution of $2.5 \%$ formic acid

515 in 50\% acetonitrile while spinning in a microcentrifuge at 13,000 rpm for 10 minutes. The

516 supernatant was removed and saved while the gel pieces were subjected to further extraction and

517 rinsing with $100 \%$ acetonitrile. The second extraction was combined with the initial extraction.

518 All solvent was removed from the extracts using a vacuum centrifuge at $37^{\circ} \mathrm{C}$. The peptides were

519 resuspended in $2.5 \%$ formic acid, $2.5 \%$ acetonitrile prior to mass spectrometry analysis.

520 Dried peptides were resuspended in Solvent A $(2.5 \% \mathrm{MeCN}, 0.15 \%$ formic acid (FA)) and

521 separated using the Easy n-LC 1200 across $15-\mathrm{cm}$ columns packed in-house with $2.7 \mu \mathrm{m} \mathrm{C18}$

522 packing material prior to analysis on the Q Exactive Plus mass spectrometer fitted with a

523 Nanospray Flex ion source $(2.2 \mathrm{kV})$ and supplied with Thermo Xcalibur 4.0 software. Peptides

524 were eluted using a $0-50 \%$ gradient of Solvent B ( $80 \% \mathrm{MeCN}, 0.15 \% \mathrm{FA})$ over $60 \mathrm{~min}$,

525 followed by 10 minutes at $95 \%$ Solvent B. The precursor scan (scan range $=360-1700 \mathrm{~m} / \mathrm{z}$,

526 resolution $=7.0 \times 10^{4}$, maximum IT $=100 \mathrm{~ms}$ ) was followed by HCD fragmentation spectra in a

527 Top-10 approach (resolution $=3.5 \times 10^{4}, \mathrm{AGC}=5.0 \times 10^{4}$, maximum $\mathrm{IT}=50 \mathrm{~ms}$, isolation

528 window $=61.6 \mathrm{~m} / \mathrm{z}$, normalized collision energy $=26 \%$, dynamic exclusion $=30 \mathrm{~s}$ ). Raw spectra

529 were searched against a forward and reverse database of tagged ZIKV proteins with common

530 contaminants added using SEQUEST with a precursor mass tolerance of $\pm 5 \mathrm{PPM}$ and a 
531 fragment ion tolerance of $\pm 0.006 \mathrm{Da}$. The following differential modifications were permitted:

532 phosphorylation of serine, threonine and tyrosine $( \pm 79.9663 \mathrm{Da})$, ubiquitylation of lysine

$533( \pm 114.0429 \mathrm{Da})$, oxidation of methionine $( \pm 15.9949 \mathrm{Da})$, carboxyamidomethylation of cysteine

$534( \pm 57.0215 \mathrm{Da})$, and acrylamidation of cysteine $( \pm 71.0371 \mathrm{Da})$. No enzyme was indicated in the

535 original search to expand the database, and the resulting hits were filtered for tryptic peptides.

536 Spectra of phosphopeptide hits were manually assessed and compared to their unphosphorylated 537 counterparts to confirm hits and determine phosphorylation site localization. To identify bound

538 human interactors, raw data were searched against a forward and reverse human database

539 containing common contaminants via SEQUEST. Trypsin was specified as the cleavage agent

540 with two missed cleavages permitted. Mass tolerances and allowed modifications were as stated

541 above. Host proteins were considered ZIKV interactors if they were identified by two or more

542 unique peptides in experimental conditions and were not present in the controls. Proteins were

543 also considered ZIKV interactors in cases where proteins were $>5$-fold enriched in experimental

544 over control conditions.

545 In our third approach, which led to the identification of ZIKV E T351 from virions,

$546 \mathrm{C} 6 / 36$ cells were infected with ZIKV at an MOI of 0.1 and then incubated at $28^{\circ} \mathrm{C}$. Four days

547 later, the supernatant was harvested and clarified by centrifugation at $5000 \mathrm{rpm}$. The clarified

548 supernatant was concentrated using 100,000 MW cut-off Centricon concentrators (Millipore).

549 The concentrate was underlayed with a $5 \mathrm{~mL}$ sucrose cushion $(24 \% \mathrm{w} / \mathrm{v}$ in $1 \mathrm{x}$ NTE buffer; NaCl-

550 Tris-EDTA) and ultracentrifuged at 105,000 $\mathrm{g}$ in a Surespin 630 Rotor (Thermo Scientific) for

$551 \quad 1.5$ hours. The pellet-associated virus was resuspended in NTE, then overlaid onto a 10-35\%

$552(\mathrm{w} / \mathrm{v}) /$ density gradient of potassium tartrate in 30\% glycerol in NTE, prepared using a Gradient

553 Master (Biocomp Instruments). Virions were banded by ultracentrifugation at 175,000 $\mathrm{g}$ 
554 overnight and collected by pipetting from the top of the gradient. Next, the virus-containing

555 fraction was removed from the gradient, placed in 100,000 MW cut-off dialysis units, and

556 dialyzed several times using $1 \times$ NTE to remove the potassium tartrate and glycerol. After

557 dialyzing overnight, virus was concentrated using 100,000 MW cut-off Centricon concentrators

558 (Millipore).

559 Concentrated ZIKV virions were inactivated at $70^{\circ} \mathrm{C}$ in $4 \mathrm{M}$ final urea in $\mathrm{TEAB}$ and then

560 prepared for liquid chromatography and tandem mass spectrometry (LC-MS/MS) as described

561 (38). Briefly, the sample was reduced, alkylated, and then digested with trypsin and LysC using

562 filter-assisted sample preparation (FASP) (39). Peptides were separated by reversed-phase

563 chromatography using a $2 \mathrm{~h}$ gradient on an Ultimate 3000 RSLCnano HPLC system (Dionex).

564 This was run in direct injection mode and coupled to a Q Exactive mass spectrometer (Thermo),

565 running in 'Top 10' data-dependent acquisition mode with fragmentation by higher-energy

566 collisional dissociation (HCD). Charge state +1 ions were rejected and fragmentation and

567 dynamic exclusion with $40 \mathrm{~s}$ was enabled. Mass spectra were annotated in MaxQuant version

$568 \quad$ 1.6.3.4 (40) with reference proteomes from Zika virus isolate

569 ZIKV/H.sapiens/Brazil/PE243/2015 (GenBank KX197192.1) and Aedes aegypti (UniProt

570 UP000008820, accessed on 2018-10-26) and the MaxQuant common contaminants list. Standard

571 settings were used, with the enzyme set as trypsin/P and fixed modifications set as

572 carbamidomethyl (C). Variable modifications were oxidation (M), acetyl (Protein N-ter),

573 phospho (STY) and, to account for artefactual modifications when inactivating in urea, carbamyl

574 (KRC). Modified spectra were considered where they could be identified in the absence of

575 artefactual carbamylation. Data from this third approach can be found at

576 https://researchdata.gla.ac.uk/1222/. 


\section{Multiple sequence alignment}

578 A multiple sequence alignment (MSA) of flavivirus FASTA-formatted sequences was generated

579 using the MUSCLE (Multiple Sequence Comparison by Log-Expectation) algorithm (41) as

580 implemented in the NIAID Virus Pathogen Database and Analysis Resource (ViPR) through the

581 web site at http://www.viprbrc.org/ (42). The Uclust parameter was set as a MUSCLE pre-

582 processor to improve both speed and quality of alignment. The alignment visualization with

583 PTM annotations was created in Jalview 2.11.1.4 (43). The following flaviviruses were aligned:

584 ZIKV H/PF/2013 (AHZ13508), ZIKV Uganda (ABI54475), ZIKV SPH2015 (ALU33341),

585 ZIKV Paraiba (ANH10698), ZIKV USA UT (AOO19564), ZIKV BeH819015 (AMA12085),

586 DENV 1 NP059433), DENV 2 (NP056776), DENV 3 (YP001621843), DENV 4 (NP073286),

587 JEV (Japanese encephalitis virus; NP059434), SLEV (Saint Louis Encephalitis Virus;

588 YP001008348), USUV (Usutu virus; AAS59401), WNV 1(YP001527877), WNV 2

589 (NP041724), AHFV (Alkhurma hemorrhagic fever virus; AAL08421), KFDV (Kyasanur forest

590 disease virus, AAQ91607), OHFV (Omsk hemorrhagic fever virus, AAQ91606), TBEV (tick-

591 borne encephalitis virus; NP043135), ENTV (Entebbe bat virus; AAV34153), MMLV (Montana

592 myotis leukoencephalitis virus, CAC82713), LAMV (Lammi virus, ACR56717), YFV

593 (NP041726), and PCV (Palm Creek virus, AGG76014).

\section{SDS-PAGE and western blotting}

595 Protein lysates were diluted in Laemmli buffer, boiled for 5 minutes, then separated on NuPAGE

596 4-12\% Bis-Tris gels with MES buffer. Protein was transferred to nitrocellulose membranes

597 using iBlot gel transfer stacks (IB301001 or IB301002, Invitrogen) and the Invitrogen iBlot

598 Device according to manufacturer instructions. Membranes were blocked with 5\% milk in PBS

599 for 1 hour and incubated overnight with primary antibody diluted in PBS which contained 5\% 
milk and 0.2\% Tween 20 (BP337, Fisher Scientific). The following day the membrane was

601 rinsed several times with TBST (tris-buffered saline with $0.1 \%$ Tween 20 ) then incubated for 1

602 hour with secondary antibody diluted in PBS containing 5\% milk, 0.2\% Tween 20, and 0.02\%

603 SDS. After secondary antibody incubation, the membrane was washed several times in TBST

604 then washed in PBS before imaging on a LI-COR Odyssey CLx system.

Primary antibodies were used for western blotting at the following concentrations: mouse anti-ZIKV E (4G2) (1:10,000) (generously provided by Baric Lab), mouse anti-streptavidin binding peptide (MAB10764, Millipore, Billerica, MA) (1:10,000), rabbit anti-actin (A2066,

Sigma-Aldrich) (1:5,000), and mouse anti-actin (A5441, Sigma-Aldrich) (1:5,000). For

610 1:20,000 dilution: IRDye 800CW goat anti-mouse (926-32210) and IRDye 680LT goat anti-

611 rabbit (926-68021).

\section{Generation of mutant ZIKV clones}

613 We used the Baric lab reverse genetics system to generate phosphomimetic and non-

614 phosphorylatable mutants as described in Widman et al. (19). ZIKV E was mutated at Y61 to

615 Y61E and Y61F and separately ZIKV E T351 was mutated to T351D and T351A. The Baric

616 reverse genetics system is composed of 4 plasmids, Fragments A through D, that encode the

617 ZIKV proteome. Fragment A was modified by GenScript from thymine to guanine at nucleotide

618 position 1599 and thymine to adenine at position 1601 to generate the Y61E phosphomimetic

619 while nucleotide 1600 was modified from adenine to thymine for the Y61F non-

620 phosphorylatable mutant. Nucleotides 2470 and 2471 in Fragment A were modified from

621 adenine and cytosine to guanine and adenine, respectively, for the T351D phosphomimetic while

622 position 2470 was modified from adenine to guanine for the T351A non-phosphorylatable 
623 mutant. Infectious recombinant ZIKV clones were generated as described in Widman et al. (19).

624 Four plasmids containing Fragments A-D, respectively, which encode for the ZIKV genome,

625 were digested with BamHI and Bsu36I for Fragment A, Bsu36I and BstXI for Fragment B,

626 BstXI and SfiI for Fragment C, and SfiI, SmaI, AlwNI for Fragment D. Restriction enzymes

627 were all acquired from New England Biolabs (Ipswich, MA). The four digested fragments were

628 ligated with T4 DNA ligase purchased from New England Biolabs. Ligated DNA was

629 precipitated with chloroform then in vitro transcribed using the mMESSAGE mMACHINE ${ }^{\mathrm{TM}}$ T7

630 ULTRA Transcription Kit from ThermoFisher Scientific. The transcribed product was then

631 electroporated into Vero E6 cells using a Gene Pulser Xcell (Bio-Rad Laboratories, Hercules,

$632 \mathrm{CA}$ ) and incubated at $37^{\circ} \mathrm{C}$ for 4 days. Cell media was collected after 4 days and passaged onto a

633 new monolayer of Vero E6 cells. Cell media collected from this passage was described as

634 "passage 1/ p.1”. Clarified cell media was titered by plaque assay using Vero E6 cells.

\section{Virus growth curves}

636 For the Y61F and Y61E mutants, six-well plates were seeded with $2 \times 10^{5}$ Vero E6 cells per well

637 and infected the following day at an MOI of 0.001. For the T351A and T351D mutants, 12-well

638 plates were seeded with $2 \times 10^{4}$ A549 cells and infected the following day at an MOI of 0.01.

639 Cell media was collected at indicated time points from separate wells. Cell media was clarified

640 by centrifugation at $1200 \mathrm{RPM}$ for 5 minutes, stored at $-80^{\circ} \mathrm{C}$, and then titered by plaque assay

641 (see plaque and focus assays below for details).

\section{$642 \quad$ Plaque and focus assays}

643 Plaque assays were used to measure infectious virus titers in several experiments as follows. Six-

644 well plates were seeded with $2.5 \times 10^{5}$ Vero E6 cells per well and the following day inoculated

645 with 10-fold serial dilutions of virus. Plates were rocked every 15 minutes for 1 hour to allow for 
646 viral absorption at $37^{\circ} \mathrm{C}$, the cells were overlaid with a solution of $0.7 \%$ agarose $(20-102$, Apex

647 Industrial Chemicals, Aberdeen, United Kingdom) in Vero E6 growth media. Wells with agarose

648 plugs were fixed 3 days later with a solution of $2.5 \%$ formaldehyde (1635-4L, Sigma-Aldrich) in

$6493 x$ PBS. Following removal of the agarose, the fixed cell monolayers were stained with $0.1 \%$

650 crystal violet (C581-100, Fisher Scientific) and 2.1\% ethanol in water.

651 Focus assays were used to assess the presence of the Y61E infectious clones after several

652 viral passages. 24-well plates were seeded with $2 \times 10^{4}$ Vero E6 cells per well and the following

653 day were inoculated with 10-fold serial dilutions of infectious viral clones. Plates were incubated

654 for 1 hour at $37^{\circ} \mathrm{C}$ with rocking every 15 minutes. After absorption, cells were overlaid with

$655 \quad 0.01 \%$ methylcellulose in Vero E6 media (see Cells and Viruses for media detail) and were left

656 in a $37^{\circ} \mathrm{C}$ incubator for 3 days. After 3 days the overlay was removed and cell monolayers were

657 fixed with 4\% formaldehyde (28906, Thermo Fisher Scientific) at room temperature, washed,

658 then permeabalized with $0.5 \%$ Triton X-100 in PBS. Cell monolayers were then blocked with

$6595 \%$ milk in PBS and thereafter incubated with 4G2 antibody $(1: 10,000)$ diluted in 5\% milk in

660 PBS for 1 hour at $37^{\circ} \mathrm{C}$. Cells were washed with PBS and then incubated with goat anti-mouse

661 secondary antibody at a 1:2000 (5450-0011, LGC Clinical Diagnostics, Inc., Milford, MA)

662 dilution in 5\% milk in PBS for 1 hour at $37^{\circ} \mathrm{C}$. Cells were washed again and then incubated with

663 TrueBlue Peroxidase Substrate (5510-0030, LGC Clinical Diagnostics, Inc.) until the formation

664 of blue foci and reaction was stopped by removing the substrate.

\section{Virus-like particle (VLP) release assay}

666 To determine the efficiency of VLP formation and release when ZIKV E contains mutations at

667 Y61 or T351, $5 \times 10^{5}$ HEK293T cells in 6-well plates were transfected with $2 \mu \mathrm{g}$ of the modified

668 PaxVax plasmids (see Plasmids for details) using $8 \mu \mathrm{g}$ of PEI per well. Twenty-four hours after 
transfection, fresh cell media was added to wells. 48 hours after transfection, cells and cell media

670 were collected. Cell media was clarified by centrifugation for 3 minutes at 1500 RPM and then

671 VLPs were lysed with 10X Triton buffer for a final dilution of $1 \mathrm{X}$ lysis buffer. Cells were

672 collected with cold PBS, centrifuged for 3 minutes at 1500 RPM, and then lysed with Triton

673 buffer. Cells and cell media were subjected to quantitative western blotting for the detection of

674 ZIKV E by way of 4G2 antibody (concentration of 1:10,000). To calculate efficiency of VLP

675 release, each ZIKV E protein value found in cells was first normalized to actin values in cells

676 (rabbit anti-actin antibody at 1:5000). VLP release efficiency was then calculated as the quotient

677 of the E protein quantity in VLPs divided by the quantity of E in cells [(EmutantVLP / Emutantcells)

678 / (EwT VLP/ EwT cells)*100].

\section{Kinase inhibition assays}

680 To determine if treating cells at the time of infection with various kinase inhibitors would impact

681 viral growth, viral challenge assays were performed. First, to screen a panel of inhibitors at a

682 fixed concentration, $2.5 \times 10^{5}$ A549 cells were seeded in 6-well plates. The next day cells were

683 infected at an MOI of 0.1 with ZIKV. After an hour of absorption at $37^{\circ} \mathrm{C}$, the inoculum was

684 removed and cells were treated with $10 \mu \mathrm{M}$ of Sunitinib (B1045, APExBIO Technology LLC,

685 Houston, TX) Bosutinib (PZ0192,Sigma-Aldrich), Defactinib (B4800, APExBIO), Imatinib

686 (9084S, Cell Signaling Technology), or DMSO vehicle control in HEK293T media. The

687 infection proceeded for 48 hours then cell media was collected, clarified by centrifugation, stored

688 at $-80^{\circ} \mathrm{C}$, and then titered by plaque assay. The percent inhibition was determined by normalizing

689 titers of drug-treated wells to the DMSO control well titers and multiplying by 100. Second, to

690 determine the $\mathrm{IC}_{50}$ of Bosutinib or Defactinib, a dose response curve was set up with drugs at

691 concentrations of $30,20,15,10,7.5,5$, and $1.25 \mu \mathrm{M}$ as well as DMSO. $2.8 \times 10^{4}$ A549 cells 
were seeded into 48 well plates. One day later, cells were infected at an MOI of 0.1. One hour

693 after absorption, the inoculum was removed and cells were treated with A549 media containing

694 drug at the listed concentrations. After 48 hours, cell media was collected, clarified by

695 centrifugation, stored at $-80^{\circ} \mathrm{C}$, and then titered by plaque assay. To determine the cell toxicity of

696 each drug, an MTT (3-(4,5-dimethylthiazol-2-yl)-2,5-diphenyltetrazolium bromide)) assay

697 (M6494, Thermo Fisher Scientific) was conducted in parallel to the infection and kinase

698 inhibitor treatment according to manufacturer instructions. A549 cells were set up in 48 well

699 plates and treated with the listed concentrations of Bosutinib. After 48 hours, cell media was

700 removed and replaced with $1.2 \mathrm{mM}$ MTT in PBS for 4 hours at $37^{\circ} \mathrm{C}$. After incubation, MTT

701 was removed and DMSO was added to each well, incubated for 10 minutes at $37^{\circ} \mathrm{C}$, and

702 absorbance was read at $540 \mathrm{~nm}$. Cell viability was determined by first normalizing the

703 absorbance readings of drug-treated cells to the DMSO control wells. Cell toxicity was

704 determined by subtracting the value of cell viability from 100 . To determine the IC 50 (half-

705 maximal inhibitory concentration) of Bosutinib and Defectinib, we used [inhibitor] versus

706 normalized response curve fitting in Prism 8.0. To determine $\mathrm{CC}_{50}$ (cytotoxic concentration

707 causing death to $50 \%$ of cells), the same Prism 8.0 curve fitting was applied to our MTT assay

708 data (inhibitor versus cell toxicity). The selectivity index (SI) of each drug was calculated by

709 dividing the $\mathrm{CC}_{50}$ by the $\mathrm{IC}_{50}$ of each drug.

710

\section{Acknowledgments}

712 We thank the NIH for the following grant support: T32 HL076122 (I.M. and C.M.Z.),

713 R21AI135265 (J.W.B.), P20RR021905 and P30GM118228 (Immunobiology and Infectious

714 Disease COBRE awards) (J.W.B.), AI107731 (R.S.B.), and the National Institute of General 
715 Medical Sciences of the NIH (P20GM103449; Vermont Biomedical Research Network

716 Bioinformatics - H.D.; Vermont Biomedical Research Network Proteomics - C.G.). We thank

717 the United Kingdom Research and Innovation Medical Research Council for the following

718 support: ZK/16-012 (D.B) and MR/N008618/1 (E.H.). We also thank the University of Vermont

719 Office of Fellowships, Opportunities and Undergraduate Research for their support of D.T.

720 Funding agencies had no role in study design, collection and analysis of data, manuscript

721 preparation or the decision to publish. We are grateful to Emergent BioSolutions, Inc. and Dr.

722 Lindsay Whitton for kindly providing critical reagents described in the Materials and Methods,

723 Svenja Hester (Advanced Proteomics Facility, University of Oxford) for performing and

724 advising on mass spectrometry, Glasgow Polyomics for computing resources and Dr. Emily

725 Bruce, the UVM Immunobiology group, and the Vermont Lung Center for technical comments

726 and insightful discussions.

728 Conflict of Interests

729 The authors declare that they have no conflict of interest.

\section{References}

732 1. Smithburn KC. Neutralizing antibodies against certain recently isolated viruses in the

733 sera of human beings residing in East Africa. J Immunol. 1952;69(2):223-34. Epub 1952/08/01.

734 PubMed PMID: 14946416.

735 2. Organization PAHOWH. Zika - Epidemiological Report Brazil2017, September 25.

736 3. Cao-Lormeau VM, Blake A, Mons S, Lastere S, Roche C, Vanhomwegen J, Dub T,

737 Baudouin L, Teissier A, Larre P, Vial AL, Decam C, Choumet V, Halstead SK, Willison HJ, 
738 Musset L, Manuguerra JC, Despres P, Fournier E, Mallet HP, Musso D, Fontanet A, Neil J,

739 Ghawche F. Guillain-Barre Syndrome outbreak associated with Zika virus infection in French

740 Polynesia: a case-control study. Lancet. 2016;387(10027):1531-9. Epub 2016/03/08. doi:

741 10.1016/S0140-6736(16)00562-6. PubMed PMID: 26948433; PMCID: PMC5444521.

742 4. Mlakar J, Korva M, Tul N, Popovic M, Poljsak-Prijatelj M, Mraz J, Kolenc M, Resman

743 Rus K, Vesnaver Vipotnik T, Fabjan Vodusek V, Vizjak A, Pizem J, Petrovec M, Avsic Zupanc

744 T. Zika Virus Associated with Microcephaly. N Engl J Med. 2016;374(10):951-8. doi:

745 10.1056/NEJMoa1600651. PubMed PMID: 26862926.

746 5. Hemonnot B, Cartier C, Gay B, Rebuffat S, Bardy M, Devaux C, Boyer V, Briant L. The

747 host cell MAP kinase ERK-2 regulates viral assembly and release by phosphorylating the p6gag

748 protein of HIV-1. J Biol Chem. 2004;279(31):32426-34. Epub 2004/05/25. doi:

749 10.1074/jbc.M313137200. PubMed PMID: 15155723.

750 6. Ziegler CM, Eisenhauer P, Bruce EA, Weir ME, King BR, Klaus JP, Krementsov DN,

751 Shirley DJ, Ballif BA, Botten J. The Lymphocytic Choriomeningitis Virus Matrix Protein PPXY

752 Late Domain Drives the Production of Defective Interfering Particles. PLoS pathogens.

753 2016;12(3):e1005501. doi: 10.1371/journal.ppat.1005501. PubMed PMID: 27010636; PMCID:

754 PMC4806877.

755 7. Ziegler CM, Eisenhauer P, Bruce EA, Beganovic V, King BR, Weir ME, Ballif BA,

756 Botten J. A novel phosphoserine motif in the LCMV matrix protein Z regulates the release of

757 infectious virus and defective interfering particles. J Gen Virol. 2016. doi: 10.1099/jgv.0.000550.

758 PubMed PMID: 27421645.

759 8. Ziegler CM, Eisenhauer P, Manuelyan I, Weir ME, Bruce EA, Ballif BA, Botten J. Host-

760 Driven Phosphorylation Appears to Regulate the Budding Activity of the Lassa Virus Matrix 
761 Protein. Pathogens. 2018;7(4). doi: 10.3390/pathogens7040097. PubMed PMID: 30544850;

762 PMCID: PMC6313517.

763 9. Bhattacharya D, Hoover S, Falk SP, Weisblum B, Vestling M, Striker R. Phosphorylation

764 of yellow fever virus NS5 alters methyltransferase activity. Virology. 2008;380(2):276-84. doi:

765 10.1016/j.virol.2008.07.013. PubMed PMID: 18757072; PMCID: PMC2583469.

766 10. Kapoor M, Zhang L, Ramachandra M, Kusukawa J, Ebner KE, Padmanabhan R.

767 Association between NS3 and NS5 proteins of dengue virus type 2 in the putative RNA replicase

768 is linked to differential phosphorylation of NS5. J Biol Chem. 1995;270(32):19100-6. PubMed

769 PMID: 7642575.

770 11. Yamauchi S, Takeuchi K, Chihara K, Sun X, Honjoh C, Yoshiki H, Hotta H, Sada K.

771 Hepatitis C Virus Particle Assembly Involves Phosphorylation of NS5A by the c-Abl Tyrosine

772 Kinase. J Biol Chem. 2015;290(36):21857-64. Epub 2015/07/24. doi: 10.1074/jbc.M115.666859.

773 PubMed PMID: 26203192; PMCID: PMC4571941.

774 12. Quintavalle M, Sambucini S, Summa V, Orsatti L, Talamo F, De Francesco R,

775 Neddermann P. Hepatitis C virus NS5A is a direct substrate of casein kinase I-alpha, a cellular

776 kinase identified by inhibitor affinity chromatography using specific NS5A

777 hyperphosphorylation inhibitors. J Biol Chem. 2007;282(8):5536-44. Epub 2006/12/15. doi:

778 10.1074/jbc.M610486200. PubMed PMID: 17166835.

779 13. Tellinghuisen TL, Foss KL, Treadaway J. Regulation of hepatitis C virion production via

780 phosphorylation of the NS5A protein. PLoS pathogens. 2008;4(3):e1000032. doi:

781 10.1371/journal.ppat.1000032. PubMed PMID: 18369478; PMCID: PMC2265800.

782 14. Henchal EA, Gentry MK, McCown JM, Brandt WE. Dengue virus-specific and flavivirus

783 group determinants identified with monoclonal antibodies by indirect immunofluorescence. Am 
J Trop Med Hyg. 1982;31(4):830-6. Epub 1982/07/01. doi: 10.4269/ajtmh.1982.31.830. PubMed

PMID: 6285749.

15. King BR, Hershkowitz D, Eisenhauer PL, Weir ME, Ziegler CM, Russo J, Bruce EA,

Ballif BA, Botten J. A map of the arenavirus nucleoprotein-host protein interactome reveals that Junin virus selectively impairs the antiviral activity of PKR. J Virol. 2017. doi:

10.1128/JVI.00763-17. PubMed PMID: 28539447.

790 16. Mukhopadhyay S, Kuhn RJ, Rossmann MG. A structural perspective of the flavivirus life

791 cycle. Nat Rev Microbiol. 2005;3(1):13-22. Epub 2004/12/21. doi: 10.1038/nrmicro1067.

792 PubMed PMID: 15608696.

793 17. Akey DL, Brown WC, Dutta S, Konwerski J, Jose J, Jurkiw TJ, DelProposto J, Ogata

794 CM, Skiniotis G, Kuhn RJ, Smith JL. Flavivirus NS1 structures reveal surfaces for associations

795 with membranes and the immune system. Science. 2014;343(6173):881-5. Epub 2014/02/08. doi:

796 10.1126/science.1247749. PubMed PMID: 24505133; PMCID: PMC4263348.

797 18. Rastogi M, Sharma N, Singh SK. Flavivirus NS1: a multifaceted enigmatic viral protein.

798 Virol J. 2016;13:131. Epub 2016/07/31. doi: 10.1186/s12985-016-0590-7. PubMed PMID:

799 27473856; PMCID: PMC4966872.

800 19. Widman DG, Young E, Yount BL, Plante KS, Gallichotte EN, Carbaugh DL, Peck KM,

801 Plante J, Swanstrom J, Heise MT, Lazear HM, Baric RS. A Reverse Genetics Platform That 802 Spans the Zika Virus Family Tree. MBio. 2017;8(2). doi: 10.1128/mBio.02014-16. PubMed

803 PMID: 28270583; PMCID: PMC5340872.

804 20. Espinosa D, Mendy J, Manayani D, Vang L, Wang C, Richard T, Guenther B, Aruri J, 805 Avanzini J, Garduno F, Farness P, Gurwith M, Smith J, Harris E, Alexander J. Passive Transfer 806 of Immune Sera Induced by a Zika Virus-Like Particle Vaccine Protects AG129 Mice Against 
807 Lethal Zika Virus Challenge. EBioMedicine. 2018;27:61-70. Epub 2017/12/23. doi:

808 10.1016/j.ebiom.2017.12.010. PubMed PMID: 29269041; PMCID: PMC5828544.

809 21. Tabata K, Arimoto M, Arakawa M, Nara A, Saito K, Omori H, Arai A, Ishikawa T,

810 Konishi E, Suzuki R, Matsuura Y, Morita E. Unique Requirement for ESCRT Factors in

811 Flavivirus Particle Formation on the Endoplasmic Reticulum. Cell Rep. 2016;16(9):2339-47.

812 Epub 2016/08/23. doi: 10.1016/j.celrep.2016.07.068. PubMed PMID: 27545892.

813 22. Giraldo MI, Xia H, Aguilera-Aguirre L, Hage A, van Tol S, Shan C, Xie X, Sturdevant

814 GL, Robertson SJ, McNally KL, Meade-White K, Azar SR, Rossi SL, Maury W, Woodson M,

815 Ramage H, Johnson JR, Krogan NJ, Morais MC, Best SM, Shi PY, Rajsbaum R. Envelope

816 protein ubiquitination drives entry and pathogenesis of Zika virus. Nature. 2020;585(7825):414-

817 9. Epub 2020/07/10. doi: 10.1038/s41586-020-2457-8. PubMed PMID: 32641828; PMCID:

818 PMC7501154.

819 23. Ziegler CM, Dang L, Eisenhauer P, Kelly JA, King BR, Klaus JP, Manuelyan I, Mattice

820 EB, Shirley DJ, Weir ME, Bruce EA, Ballif BA, Botten J. NEDD4 family ubiquitin ligases

821 associate with LCMV Z's PPXY domain and are required for virus budding, but not via direct

822 ubiquitination of Z. PLoS pathogens. 2019;15(11):e1008100. Epub 2019/11/12. doi:

823 10.1371/journal.ppat.1008100. PubMed PMID: 31710650; PMCID: PMC6874086

824 24. Pierson TC, Diamond MS. Degrees of maturity: the complex structure and biology of

825 flaviviruses. Curr Opin Virol. 2012;2(2):168-75. Epub 2012/03/27. doi:

826 10.1016/j.coviro.2012.02.011. PubMed PMID: 22445964; PMCID: PMC3715965.

827 25. Bhattacharya D, Mayuri, Best SM, Perera R, Kuhn RJ, Striker R. Protein kinase G

828 phosphorylates mosquito-borne flavivirus NS5. J Virol. 2009;83(18):9195-205. doi:

829 10.1128/JVI.00271-09. PubMed PMID: 19587048; PMCID: PMC2738234. 
830 26. Morozova OV, Tsekhanovskaya NA, Maksimova TG, Bachvalova VN, Matveeva VA,

831 Kit Y. Phosphorylation of tick-borne encephalitis virus NS5 protein. Virus Res. 1997;49(1):9-15.

832 PubMed PMID: 9178492.

833 27. Lemay KL, Treadaway J, Angulo I, Tellinghuisen TL. A hepatitis C virus NS5A

834 phosphorylation site that regulates RNA replication. J Virol. 2013;87(2):1255-60. Epub

835 2012/11/02. doi: 10.1128/JVI.02154-12. PubMed PMID: 23115292; PMCID: PMC3554050.

836 28. Valencia HJ, de Aguiar M, Costa MA, Mendonca DC, Reis EV, Arias NEC, Drumond

837 BP, Bonjardim CA. Evaluation of kinase inhibitors as potential therapeutics for flavivirus

838 infections. Arch Virol. 2021;166(5):1433-8. Epub 2021/03/09. doi: 10.1007/s00705-021-05021-

839 1. PubMed PMID: 33683474; PMCID: PMC7938686.

840 29. Lee CY, Henricks DM, Skelley GC, Grimes LW. Growth and hormonal response of

841 intact and castrate male cattle to trenbolone acetate and estradiol. J Anim Sci. 1990;68(9):2682-

842 9. Epub 1990/09/01. doi: 10.2527/1990.6892682x. PubMed PMID: 2211398.

843 30. Rausch K, Hackett BA, Weinbren NL, Reeder SM, Sadovsky Y, Hunter CA, Schultz DC,

844 Coyne CB, Cherry S. Screening Bioactives Reveals Nanchangmycin as a Broad Spectrum

845 Antiviral Active against Zika Virus. Cell Rep. 2017;18(3):804-15. Epub 2017/01/19. doi:

846 10.1016/j.celrep.2016.12.068. PubMed PMID: 28099856; PMCID: PMC5270376.

847 31. Liang Q, Luo Z, Zeng J, Chen W, Foo SS, Lee SA, Ge J, Wang S, Goldman SA, 848 Zlokovic BV, Zhao Z, Jung JU. Zika Virus NS4A and NS4B Proteins Deregulate Akt-mTOR

849 Signaling in Human Fetal Neural Stem Cells to Inhibit Neurogenesis and Induce Autophagy.

850 Cell Stem Cell. 2016;19(5):663-71. doi: 10.1016/j.stem.2016.07.019. PubMed PMID: 27524440;

851 PMCID: PMC5144538. 
852 32. Chiramel AI, Best SM. Role of autophagy in Zika virus infection and pathogenesis. Virus

853 Res. 2018;254:34-40. Epub 2017/09/14. doi: 10.1016/j.virusres.2017.09.006. PubMed PMID:

854 28899653; PMCID: PMC5844781.

855 33. Scaturro P, Stukalov A, Haas DA, Cortese M, Draganova K, Plaszczyca A,

856 Bartenschlager R, Gotz M, Pichlmair A. An orthogonal proteomic survey uncovers novel Zika

857 virus host factors. Nature. 2018;561(7722):253-7. Epub 2018/09/05. doi: 10.1038/s41586-018-

858 0484-5. PubMed PMID: 30177828.

859 34. Donald CL, Brennan B, Cumberworth SL, Rezelj VV, Clark JJ, Cordeiro MT, Freitas de

860 Oliveira Franca R, Pena LJ, Wilkie GS, Da Silva Filipe A, Davis C, Hughes J, Varjak M,

861 Selinger M, Zuvanov L, Owsianka AM, Patel AH, McLauchlan J, Lindenbach BD, Fall G, Sall

862 AA, Biek R, Rehwinkel J, Schnettler E, Kohl A. Full Genome Sequence and sfRNA Interferon

863 Antagonist Activity of Zika Virus from Recife, Brazil. PLoS Negl Trop Dis.

864 2016;10(10):e0005048. Epub 2016/10/06. doi: 10.1371/journal.pntd.0005048. PubMed PMID:

866 35. Alzhanova D, Corcoran K, Bailey AG, Long K, Taft-Benz S, Graham RL, Broussard GS,

867 Heise M, Neumann G, Halfmann P, Kawaoka Y, Baric RS, Damania B, Dittmer DP. Novel

868 modulators of p53-signaling encoded by unknown genes of emerging viruses. PLoS pathogens.

869 2021;17(1):e1009033. Epub 2021/01/08. doi: 10.1371/journal.ppat.1009033. PubMed PMID:

870 33411764; PMCID: PMC7790267

871 36. Klaus JP, Eisenhauer P, Russo J, Mason AB, Do D, King B, Taatjes D, Cornillez-Ty C,

872 Boyson JE, Thali M, Zheng C, Liao L, Yates JR, 3rd, Zhang B, Ballif BA, Botten JW. The

873 intracellular cargo receptor ERGIC-53 is required for the production of infectious arenavirus, 
874 coronavirus, and filovirus particles. Cell Host Microbe. 2013;14(5):522-34. Epub 2013/11/19.

875 doi: 10.1016/j.chom.2013.10.010. PubMed PMID: 24237698; PMCID: 3999090.

876 37. Cornillez-Ty CT, Liao L, Yates JR, 3rd, Kuhn P, Buchmeier MJ. Severe acute respiratory

877 syndrome coronavirus nonstructural protein 2 interacts with a host protein complex involved in

878 mitochondrial biogenesis and intracellular signaling. J Virol. 2009;83(19):10314-8. Epub

879 2009/07/31. doi: JVI.00842-09 [pii] 10.1128/JVI.00842-09. PubMed PMID: 19640993; PMCID:

8802748024.

881 38. Hutchinson EC, Stegmann M. Purification and Proteomics of Influenza Virions. Methods

882 Mol Biol. 2018;1836:89-120. Epub 2018/08/29. doi: 10.1007/978-1-4939-8678-1_5. PubMed

883 PMID: 30151570.

884 39. Wisniewski JR, Zougman A, Nagaraj N, Mann M. Universal sample preparation method

885 for proteome analysis. Nat Methods. 2009;6(5):359-62. Epub 2009/04/21. doi:

886 10.1038/nmeth.1322. PubMed PMID: 19377485.

887 40. Tyanova S, Temu T, Cox J. The MaxQuant computational platform for mass

888 spectrometry-based shotgun proteomics. Nat Protoc. 2016;11(12):2301-19. Epub 2016/11/04.

889 doi: 10.1038/nprot.2016.136. PubMed PMID: 27809316.

890 41. Edgar RC. MUSCLE: multiple sequence alignment with high accuracy and high

891 throughput. Nucleic Acids Res. 2004;32(5):1792-7. Epub 2004/03/23. doi: 10.1093/nar/gkh340.

892 PubMed PMID: 15034147; PMCID: PMC390337.

893 42. Pickett BE, Sadat EL, Zhang Y, Noronha JM, Squires RB, Hunt V, Liu M, Kumar S,

894 Zaremba S, Gu Z, Zhou L, Larson CN, Dietrich J, Klem EB, Scheuermann RH. ViPR: an open

895 bioinformatics database and analysis resource for virology research. Nucleic Acids Res. 
896 2012;40(Database issue):D593-8. Epub 2011/10/19. doi: 10.1093/nar/gkr859. PubMed PMID:

897 22006842; PMCID: PMC3245011.

898 43. Waterhouse AM, Procter JB, Martin DM, Clamp M, Barton GJ. Jalview Version 2--a

899 multiple sequence alignment editor and analysis workbench. Bioinformatics. 2009;25(9):1189-

900 91. Epub 2009/01/20. doi: 10.1093/bioinformatics/btp033. PubMed PMID: 19151095; PMCID:

901 PMC2672624. 


\section{Figure Legends}

\section{Figure 1. Discovery of post-translational modifications on the ZIKV proteome.}

904 (A) Depictions of i) a ZIKV particle with its structural proteins indicated and ii) the organization

905 of the ZIKV positive-strand RNA genome and its encoded ORFeome.

906 (B) Overview of the workflow for discovery of post-translational modifications on ZIKV

907 proteins in the settings of viral infection or plasmid-based expression of ZIKV proteins. IP,

908 immunoprecipitation; AP, affinity purification.

909 (C, D, and E) Western blots and Coomassie stained SDS-page gels of affinity purified ZIKV E

910 from ZIKV infected cells (C), authentic ZIKV particles (D), or the indicated SBP-tagged ZIKV

911 proteins (E). For (C and D), Vero E6 cells were infected with ZIKV strain BeH819015 at an

912 MOI of 0.1. Cells (C) and media (D) were collected 72 hours and 96 hours later, respectively. In

913 (C), infected cells were lysed in Triton-X buffer and intracellular ZIKV E was purified using the

914 anti-E antibody 4G2 and magnetic protein G beads. As a control, we performed

915 immunoprecipitation of uninfected (mock) cellular lysates with the 4G2 antibody. In (D), viral

916 particles were immunoprecipitated from clarified supernatants using the 4G2 antibody and

917 magnetic protein G beads. Control conditions included (i) immunoprecipitation of virus-

918 containing supernatants with a non-specific mouse IgG antibody and (ii) immunoprecipitation of

919 an uninfected (mock) supernatant with the 4G2 antibody. For (E), to purify ZIKV proteins

920 expressed from plasmid, we engineered plasmids to encode the indicated ZIKV ORFs with a C-

921 terminal streptavidin-binding protein (SBP) tag. HEK293T cells were transfected with a plasmid

922 encoding the indicated SBP-tagged ZIKV protein or, as a control, an empty vector (V). Two days

923 after transfection, the cells were lysed in Triton-X buffer and ZIKV proteins were affinity

924 purified using streptavidin-coated magnetic beads (labeled as Anti-SBP in panels). In panels (C- 
925 E), for both antibody- and streptavidin-based purifications, captured protein mixtures were

926 orthogonally separated using SDS-PAGE, followed by in-gel processing for subsequent mass

927 spectrometry analysis to discover post-translational modifications or interacting host proteins.

928 The molecular weight in $\mathrm{kDa}$, viral proteins (yellow text and arrows), and immunoglobulin

929 bands are labeled. Note that the asterisks in (E) indicate monomeric streptavidin that was eluted

930 off the streptavidin beads when boiled.

931

932 Figure 2. Location of post-translational modification sites on ZIKV proteins. Phosphosites

933 and ubiquitination sites are marked in green and light purple, respectively. For each ZIKV

934 protein, individual domains or specific features are color coded with the text label displayed in

935 the matching color in each instance.

936 (A and B) Location of the Y61 and T351 phosphosites on ZIKV E (A) or location of all post-

937 translational modifications on ZIKV E (B). In both (A and B), PDB ID: 5JHM was used and one

938 copy of $\mathrm{E}$ is shown.

939 (C) ZIKV E - M heterodimer (PDB ID: 5IZ7). Y61 and T351 are labeled on the E ectodomain.

940 ZIKV M phosphosites S16 and T18 are labeled on the M protein.

941 (D) PTM locations on ZIKV NS1 (PDB ID: 5GS6).

942 (E) ZIKV NS2B - NS3 protease complex shown in close conformation (PDB ID: 5GPI) with

943 labeled phosphosites on ZIKV NS2B.

944 (F) ZIKV NS5 (PDB ID: 5TMH) phosphosites. RdRp, RNA-dependent RNA polymerase;

945 MTase, methyltransferase domain. 


\section{Figure 3. Tyrosine 61 and threonine 351 on the ZIKV E protein are critical for viral}

\section{8 propagation at the stage of viral budding.}

949 (A-C) Overview of the reverse genetics approach used to recover infectious ZIKV clones bearing

950 mutations at Y61 or T351 in the E protein (A). For each recovery attempt, full-length infectious

951 RNAs were transcribed from a cDNA template of the viral genome. The RNAs were

952 electroporated into Vero E6 cells and 3 days later supernatants from these cultures were screened

953 for the presence of infectious ZIKV particles by either viral plaque assay (B) or focus assay (C).

954 In (C), the rZIKV E Y61E clone was passaged 2 additional times due to the absence of

955 detectable plaques or foci after passage 1. The Y61E passage 3 material showed infectious virus

956 and this rLCMV had mutated from a glutamic acid to a valine at position 61.

957 (D and E) The growth kinetics of the indicated rZIKV E Y61 mutants (D) or T351 mutants (E)

958 was determined by infecting Vero E6 cells at an MOI of 0.001 (D) or A549 cells at an MOI of

$9590.01(\mathrm{E})$ with these viruses and measuring the infectious particles released by plaque assay at 24,

$96048,72,96,120$, or 144 hours after infection. Data represent the mean \pm SEM from three (D) or

961 two (E) independent biological replicates. For statistical analysis, data were analyzed via mixed-

962 effect analysis (two-way ANOVA) with Holm-Sidak's test for multiple comparisons in Prism

9638.0.

964 (F) The budding activity of WT, Y61- or T351-mutant E proteins was measured by a virus-like

965 particle (VLP) assay. VLPs were generated by transfection of HEK293T cells with plasmid that

966 encodes ZIKV prM and E (either WT E or the indicated E mutants). The quantity of ZIKV E

967 released into the supernatant vs retained in cells was measured by quantitative western blot and

968 budding efficiency was determined as described in the Methods. Data represent the mean $\pm \mathrm{SEM}$ 
969 from three (Y61 mutants) or four (T351 mutants) independent biological replicates. Statistical

970 significance was determined in Prism 8.0 software using a one-way ANOVA.

971 For the indicated statistical tests in (D-F): *, $\mathrm{P}<0.05 ; * * ; \mathrm{P}<0.01 ; * * * ; \mathrm{P}<0.001$.

972

973 Figure 4. Host kinase interactions the ZIKV proteome and effects of kinase inhibitors on

974 ZIKV growth.

975 (A) Host kinases that interact with ZIKV proteins. Shown are kinases that had the greatest

976 number of tryptic peptides (top 10 for each ZIKV protein) detected by mass spectrometry and/or

977 were predicted by Scansite 4.0 to phosphorylate one or more of the phosphosites identified in

978 this study. Black circles denote kinases that interacted with 5 viral proteins. ZIKV proteins with

979 detectable phosphosites in this study are indicated with a "P". Drugs known to inhibit specific

980 kinases are listed; drugs with FDA approval are bolded.

981 (B) Efficacy of kinase inhibitors in restricting ZIKV growth. A549 cells were infected with

982 ZIKV at a MOI of 0.1 and 1 hour later, the inoculum was removed and cells were treated with 10

$983 \mu \mathrm{M}$ of the indicated drug or, as a control, DMSO (vehicle). Two days later infectious virus

984 measured in the supernatants via plaque assay. Data represent mean $\pm \mathrm{SEM}$ from three

985 independent biological replicates. Statistical significance was determined in Prism 8.0 software

986 via one-way ANOVA with Holm-Sidak's test for multiple comparisons. *, $\mathrm{P}<0.05$

987 (C and D) IC50 determination for Defactinib and Bosutinib inhibition of ZIKV growth. A549

988 cells were infected with ZIKV at a MOI of 0.1 and 1 hour later, the inoculum was removed and

989 cells were treated with the indicated doses of Bosutinib or Defactinib. Two days later infectious

990 virus was measured in the supernatants via plaque assay. In parallel, the cytotoxicity of each

991 drug at these same doses was determined via MTT assay as described in the Methods. Data 
992

993

994

995

996

997

998

999

1000

1001

1002

1003

1004

1005

1006

1007

1008

1009

1010

1011 after transfection, cells were treated with $\mathrm{DMSO}, \mathrm{H}_{2} \mathrm{O}_{2}$, or Calyculin A for 30 minutes and then

1012 lysed in Triton-X buffer. SBP-tagged ZIKV proteins were affinity purified using streptavidin-

1013 coated magnetic beads and the captured protein mixtures were orthogonally separated using

1014 SDS-PAGE, followed by in-gel processing for subsequent mass spectrometry analysis to 
1015 discover post-translational modifications or interacting host proteins. The molecular weight in

$1016 \mathrm{kDa}$, viral proteins (yellow text and arrows), and immunoglobulin bands are labeled. Note that

1017 the asterisks in indicate monomeric streptavidin that was eluted off of the streptavidin beads

1018 when boiled.

1020 Figure S3 Purification of plasmid-expressed ZIKV NS1, NS4A, and NS2B in the setting of

1021 phosphatase inhibition for mass spectrometry analysis. Western blots and Coomassie stained

1022 SDS-page gels of purified SBP-tagged ZIKV proteins. HEK293T cells were transfected with a

1023 plasmid encoding the indicated SBP-tagged ZIKV protein or, as a control, an empty vector (V).

1024 Two days after transfection, cells were treated with $\mathrm{DMSO}, \mathrm{H}_{2} \mathrm{O}_{2}$, or Calyculin A for 30 minutes

1025 and then lysed in Triton-X buffer. SBP-tagged ZIKV proteins were affinity purified using

1026 streptavidin-coated magnetic beads and the captured protein mixtures were orthogonally

1027 separated using SDS-PAGE, followed by in-gel processing for subsequent mass spectrometry

1028 analysis to discover post-translational modifications or interacting host proteins. The molecular

1029 weight in kDa, viral proteins (yellow text and arrows), and immunoglobulin bands are labeled.

1030 Note that the asterisks in indicate monomeric streptavidin that was eluted off streptavidin beads

1031 when boiled.

1032

1033 Figure S4. Purification of plasmid expressed ZIKV NS4B and NS5 in the setting of

1034 phosphatase inhibition for mass spectrometry analysis. Western blots and Coomassie stained

1035 SDS-page gels of purified SBP-tagged ZIKV proteins. HEK293T cells were transfected with a

1036 plasmid encoding the indicated SBP-tagged ZIKV protein or, as a control, an empty vector (V).

1037 Two days after transfection, cells were treated with $\mathrm{DMSO}, \mathrm{H}_{2} \mathrm{O}_{2}$, or Calyculin A for 30 minutes 
1038 and then lysed in Triton-X buffer. SBP-tagged ZIKV proteins were affinity purified using

1039 streptavidin-coated magnetic beads and the captured protein mixtures were orthogonally

1040 separated using SDS-PAGE, followed by in-gel processing for subsequent mass spectrometry

1041 analysis to discover post-translational modifications or interacting host proteins. The molecular

1042 weight in kDa, viral proteins (yellow text and arrows), and immunoglobulin bands are labeled.

1043 Note that the asterisks in indicate monomeric streptavidin that was eluted off of the streptavidin

1044 beads when boiled.

1045

1046 Figure S5. PTMs labeled on an electrostatic model of ZIKV E dimer (PDB ID: 5JHM). Blue

1047 indicates positive charges while red indicates negative charges. (A) Electrostatic view of ZIKV E

1048 dimer. (B) rotated to the negatively charged "face". (C) "Side-view" positioning showing the

1049 neutral border of electrostatically labeled ZIKV E dimer along with location of post-translational

1050 modification.

1051

1052 Figure S6. ZIKV E Y61 interactions with neighboring residues and a view of the junction

1053 of ZIKV E and M. (A) Zoomed in view of the junction of ZIKV E (yellow) and M heterodimer

1054 (dark purple) with M phosphosites labeled in green. (B) Zoomed in view of Y61 on ZIKV E.

1055 Y61 is labeled in green while residues in close proximity, N207 and E262, are labeled in yellow.

1057 Figure S7. NS2A and NS3 did not express at sufficiently high levels for mass spectrometry

1058 analysis. Attempts were made to express and purify NS2A and NS3 via plasmid transfection of

1059 mammalian cells. HEK293T cells were transfected with plasmids that encoded ZIKV proteins

1060 with either a C-terminal 3x FLAG-tag (A) or a SBP tag (B). Two days later, cells were lysed and 
bioRxiv preprint doi: https://doi.org/10.1101/2021.11.24.469793; this version posted November 25, 2021. The copyright holder for this preprint

(which was not certified by peer review) is the author/funder, who has granted bioRxiv a license to display the preprint in perpetuity. It is made available under aCC-BY-NC-ND 4.0 International license.

1061 tag-based protein purifications were attempted with an anti-FLAG antibody and magnetic protein

1062 G beads (A) or magnetic streptavidin beads (B).

1063

1064 
1065 Table 1. Phosphorylation and ubiquitination sites on the ZIKV proteome.

\begin{tabular}{|c|c|c|c|c|c|}
\hline \multirow[b]{2}{*}{$\begin{array}{l}\text { ZIKV } \\
\text { Protein }\end{array}$} & \multirow[b]{2}{*}{$\begin{array}{l}\text { Post-translational } \\
\text { modifications }\end{array}$} & \multicolumn{3}{|c|}{ Treatment $^{a}$} & \multirow[b]{2}{*}{$\begin{array}{l}\text { Predicted Kinases/lnteracting } \\
\text { kinases/ Closely-related kinases } \\
\text { discovered }^{\text {b }}\end{array}$} \\
\hline & & DMSO & $\mathrm{H}_{2} \mathrm{O}_{2}$ & Calyculin A & \\
\hline $\mathbf{C}$ & None found & & & & \\
\hline M & $\mathrm{S} 16 \neq^{\mathrm{c}}$ & & & $\checkmark$ & $\begin{array}{l}\text { PRKAA1, NEK1, NEK3, NEK4, NEK5, } \\
\text { NEK8, NEK10 (low), CLK2, ATM, } \\
\text { PRKDC (min) }\end{array}$ \\
\hline & T18 & & & $\checkmark$ & $\begin{array}{l}\text { GSK3B, AKT1, PRKACG (low), } \\
\text { CAMK2B, PRKCE, PRKAA1, AURKA, } \\
\text { AURKB (min) }\end{array}$ \\
\hline \multirow[t]{24}{*}{$\mathbf{E}$} & $Y 61^{\wedge d}$ & & & & FGR \\
\hline & S142 & $\checkmark$ & $\checkmark$ & $\checkmark$ & GSK3B, AURKB, NEK3 (min) \\
\hline & S149 & $\checkmark$ & $\checkmark$ & $\checkmark$ & PRKAA1, NEK5 (min) \\
\hline & T156 & $\checkmark$ & & & GSK3B, PLK1, PRKAA1 (min) \\
\hline & $S 173^{\wedge}$ & $\checkmark$ & $\checkmark$ & $\checkmark$ & CDK1, CDK5 (low), MAPK3 (min) \\
\hline & T179 & & $\checkmark$ & $\checkmark$ & $\begin{array}{l}\text { PLK1, PRKCD, PRKCE, PRKAA1, } \\
\text { AURKA, NEK6, NEK7, NEK10 (min) }\end{array}$ \\
\hline & S185\# & $\checkmark$ & & $\checkmark$ & \\
\hline & T205 & & & $\checkmark$ & $\begin{array}{l}\text { NEK7 (med), NEK6, NEK8, NEK9 (low), } \\
\text { NEK } 10 \text { (min) }\end{array}$ \\
\hline & T231 & $\checkmark$ & $\checkmark$ & $\checkmark$ & NEK6, MAPK3 (min) \\
\hline & T233 & & $\checkmark$ & $\checkmark$ & CDK1, CDK5 (low) MAPK3 (low) \\
\hline & T254 & & & $\checkmark$ & $\begin{array}{l}\text { PRKACG, AURKB (med), PRKCD, } \\
\text { PRKAA1, AURKA (low), CAMK2G, } \\
\text { PRKCE, PRKD1, NEK2, NEK4, NEK5 } \\
\text { (min) }\end{array}$ \\
\hline & S306^ & & & $\checkmark$ & PLK1, AKT1, AURKA (min) \\
\hline & T335 & $\checkmark$ & $\checkmark$ & $\checkmark$ & CSNK1G2 (min) \\
\hline & T351‡ & $\checkmark$ & $\checkmark$ & $\checkmark$ & CAMK2G (min) \\
\hline & T353 & $\checkmark$ & $\checkmark$ & $\checkmark$ & CDK1, CDK5, MAPK3 (low) \\
\hline & $\mathrm{T} 360^{\wedge \wedge \mathrm{e}}$ & & & $\checkmark$ & AKT1 (low), PRKD1, MAPK3 (min) \\
\hline & T366 & & & $\checkmark$ & \\
\hline & S368 & & & $\checkmark$ & \\
\hline & S372 & & & $\checkmark$ & NEK5 (low), CSNK1G2, PLK1 (min) \\
\hline & K93^ & $\checkmark$ & $\checkmark$ & $\checkmark$ & \\
\hline & $\mathrm{K} 118^{\wedge}$ & & $\checkmark$ & & \\
\hline & K246 & $\checkmark$ & & & \\
\hline & $\mathrm{K} 281^{\wedge}$ & $\checkmark$ & $\checkmark$ & & \\
\hline & K290 & $\checkmark$ & $\checkmark$ & & \\
\hline \multirow[t]{5}{*}{ NS1 } & $T 17 \neq^{* f}$ & $\checkmark$ & & & $\begin{array}{l}\text { PRKD1, PRKCZ (low) AKT1, PRKACG, } \\
\text { PRKCA, PRKCD (min) }\end{array}$ \\
\hline & Y22* & $\checkmark$ & & & FGR, LCK, SCR (min) \\
\hline & S132 & $\checkmark$ & $\checkmark$ & $\checkmark$ & $\begin{array}{l}\text { PLK1 (med), NEK5 (low), CAMK2G, } \\
\text { PRKCD, PDPK1, NEK1, NEK5, NEK9, } \\
\text { NEK10 (min) }\end{array}$ \\
\hline & Y175 & & $\checkmark$ & & INSR (min) \\
\hline & $\mathrm{S} 176$ & $\checkmark$ & & $\checkmark$ & PLK1 (low) \\
\hline
\end{tabular}




\begin{tabular}{|c|c|c|c|c|c|}
\hline & T186 & & & $\checkmark$ & CDK1 (min) \\
\hline & Y200 & & $\checkmark$ & & NEK10 (min) \\
\hline & $\mathrm{T} 233^{* * \mathrm{~g}}$ & & $\checkmark$ & & CSNK1G2 (min) \\
\hline & $\mathrm{S} 239 * * \wedge \wedge$ & & $\checkmark$ & & \\
\hline & S246^ & & & $\checkmark$ & PRKD1 (min) \\
\hline & S348^^ & $\checkmark$ & $\checkmark$ & $\checkmark$ & $\begin{array}{l}\text { NEK2 (med), NEK1, NEK3, NEK4, } \\
\text { NEK8, NEK10 (low), NEK5, NEK6, } \\
\text { NEK9 (min) }\end{array}$ \\
\hline & K141 & & $\checkmark$ & & \\
\hline NS2B & $\mathrm{S} 71^{\wedge}$ & & $\checkmark$ & $\checkmark$ & CDK1, CDK5 (low) \\
\hline NS4A & None found & & & & \\
\hline NS2A & No expression & & & & \\
\hline NS3 & No expression & & & & \\
\hline NS4B & $\begin{array}{l}\mathrm{S} 21 \#^{\mathrm{h}} / \mathrm{S} 218 \# \neq / \\
\mathrm{T} 219 \#\end{array}$ & & $\checkmark$ & & $\begin{array}{l}\text { PRKAA1 (low), NEK6, NEK8, NEK9, } \\
\text { GSK3B, PLK1, PDPK1, CDK1 (min) }\end{array}$ \\
\hline \multirow[t]{4}{*}{ NS5 } & S234 & & & $\checkmark$ & CDK1 (min) \\
\hline & $\mathrm{S} 237^{\wedge \wedge}$ & & & $\checkmark$ & PRKAA1, PRKDC, NEK3, NEK10 (min) \\
\hline & $\mathrm{T}^{29}{ }^{\wedge}$ & $\checkmark$ & & & $\begin{array}{l}\text { PRKCD, PRKCE, NEK6, NEK7, NEK8 } \\
\text { (min) }\end{array}$ \\
\hline & $\mathrm{S} 663^{\wedge \wedge}$ & $\checkmark$ & $\checkmark$ & $\checkmark$ & CLK2 (min) \\
\hline
\end{tabular}

${ }^{\mathrm{a}}$ Cell treatment conditions (DMSO, $\mathrm{H}_{2} \mathrm{O}_{2}$, Calyculin A, or, in the case of Y61, no treatment) under

1067 peptides were detected are indicated with check marks.

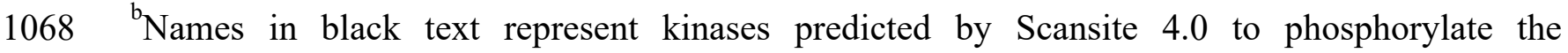

1069 corresponding residue listed in a given row. Purple text represents predicted kinases that were also

1070 interacting partners of the indicated viral protein for a particular row. Blue text represents predicted

1071 kinases that were not found to interact with viral proteins but are in the same kinase cascade or has

1072 shared homology with an interacting kinase. Predicted kinases are followed by Scansite 4.0

1073 stringency levels (high, med/medium, low, or min/minimum). High, medium, low, minimum

1074 stringency indicates that the motif identified in the ZIKV polypeptide sequence is within the top

$10750.2 \%, 1 \%, 5 \%$ and $15 \%$ of sequence matches, respectively.

1076 cłPhosphosite conserved only among ZIKV strains.

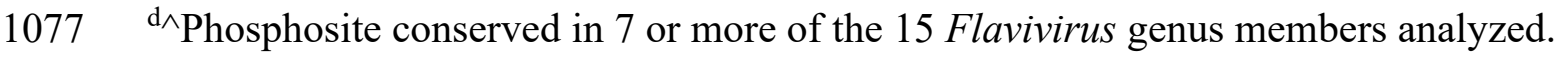

1078 e^^ Phosphosite highly conserved among 13 or more Flavivirus genus members analyzed. 
1079 -For full details of the amino acid conservation analysis related to ${ }^{\mathrm{c}, \mathrm{d}, \mathrm{e}}$, see the "multiple sequence

1080 alignment" section of the Methods.

$1081 \mathrm{f}^{*}$ Mass spectrometry data not sufficient to distinguish between NS1 sites T17 and Y22; there was

1082 evidence for both sites.

$1083{ }^{\mathrm{g}^{* *}}$ Evidence for both NS1 T233 and S239 sites.

1084 h\#Phosphosite was located to one of these three locations. 


\section{Figure 1}

A
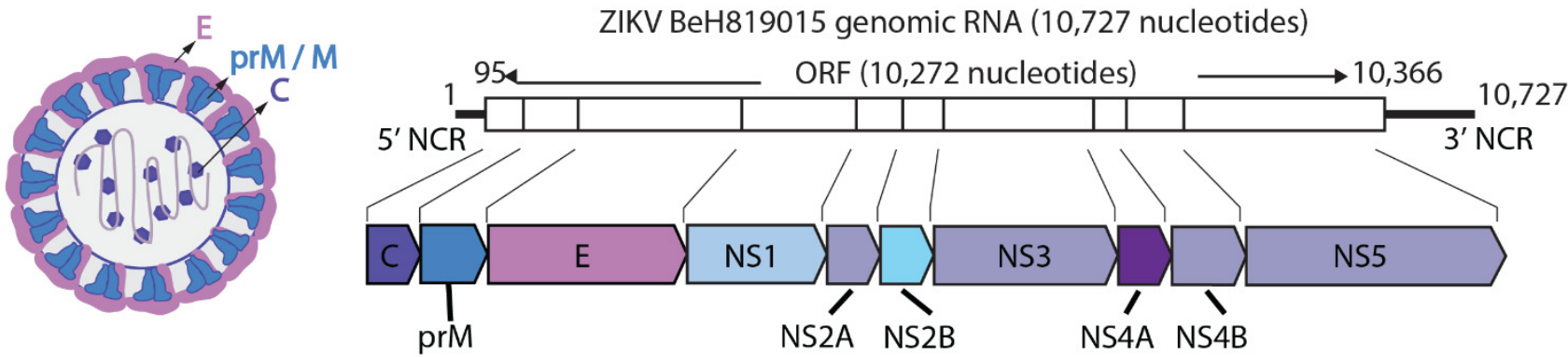

B

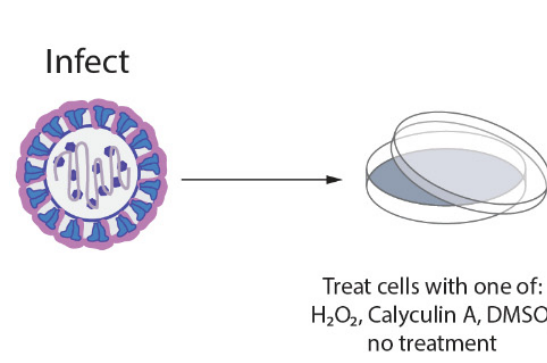

Collect cells

Transfect
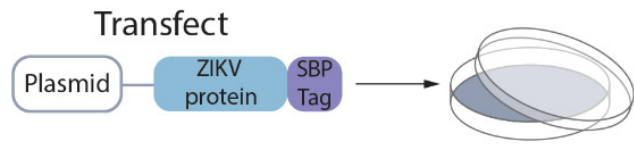

Collect cells

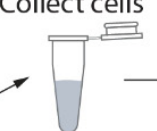

Collect media
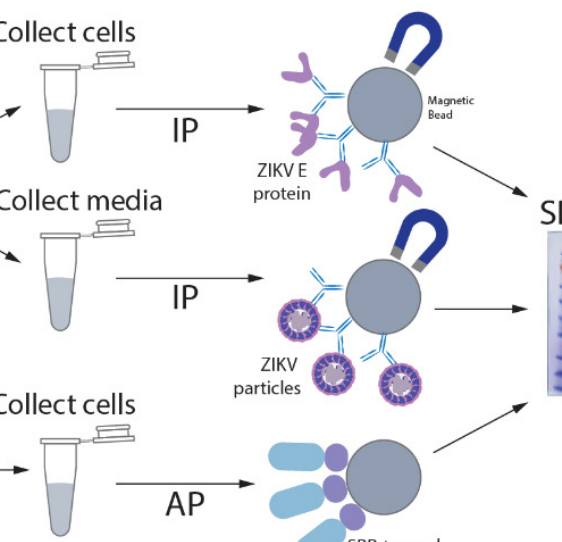

SDS-PAGE

Post-translational $\longrightarrow$ modification identification by mass spectometry

C Infected cells
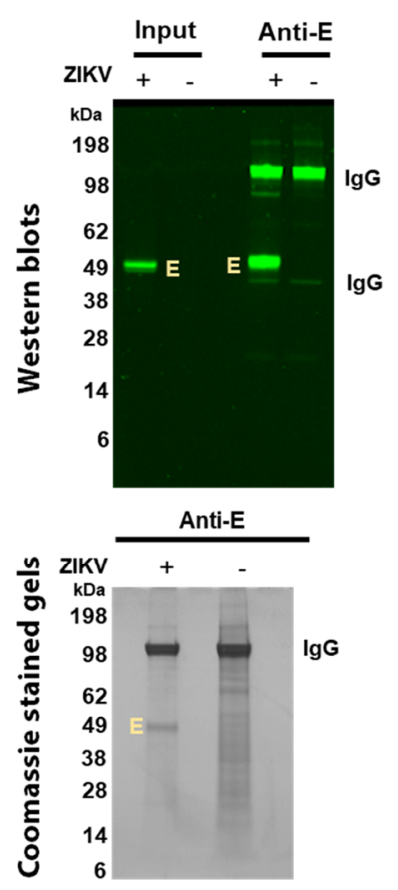

D Virion capture
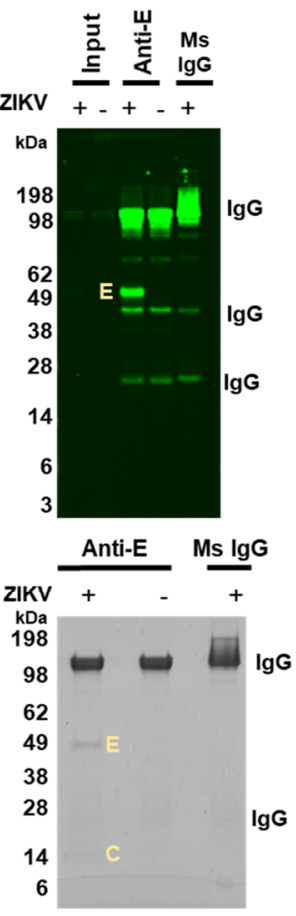

E

SBP-tagged transfected ZIKV proteins

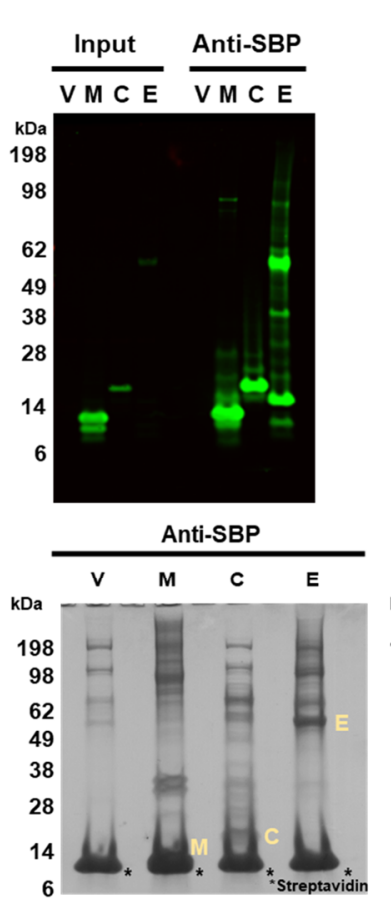

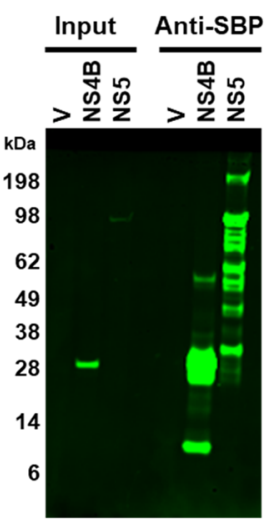

Anti-SBP

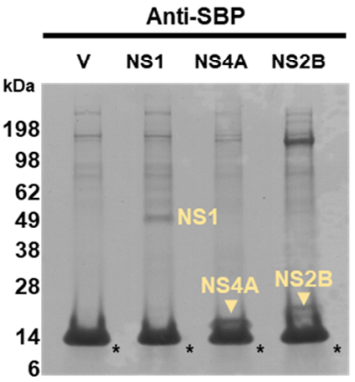

Anti-SBP

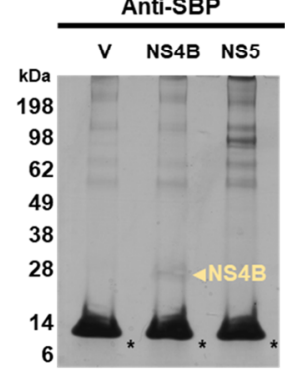


bioRxiv preprint doi: https://doi.org/10.1101/2021.11.24.469793; this version posted November 25, 2021. The copyright holder for this preprint (which was not certified by peer review) is the author/funder, who has granted bioRxiv a license to display the preprint in perpetuity. It is made available under aCC-BY-NC-ND 4.0 International license.

\section{Figure 2}

A

ZIKV E (one copy)

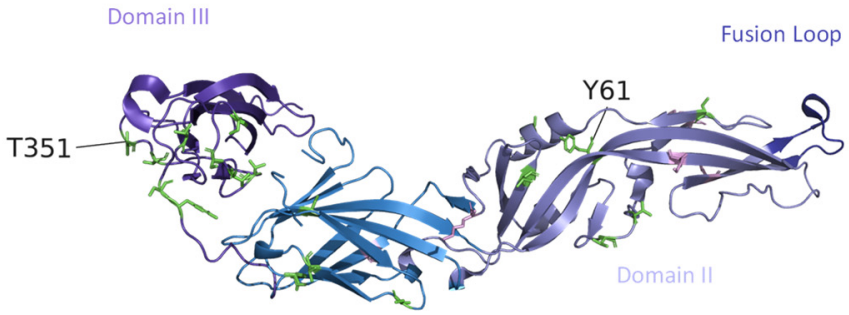

Domain I

B

\section{ZIKV E (one copy)}

Domain III

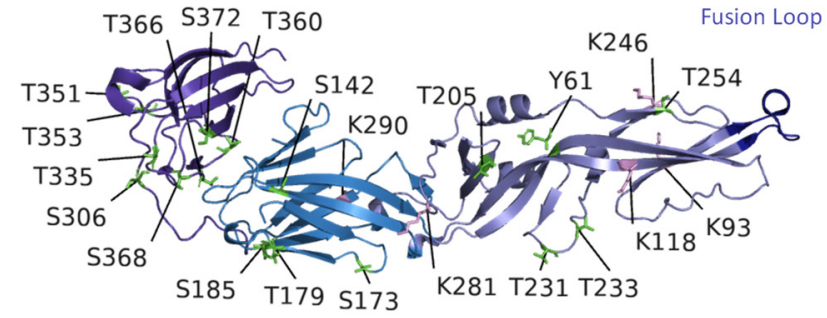

Domain I

Domain II

D

ZIKV E and M heterodimer

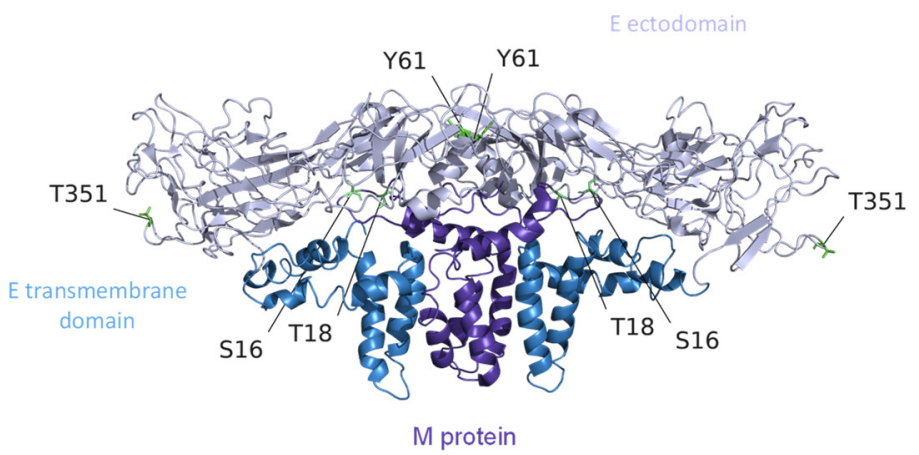

$\mathbf{E}$

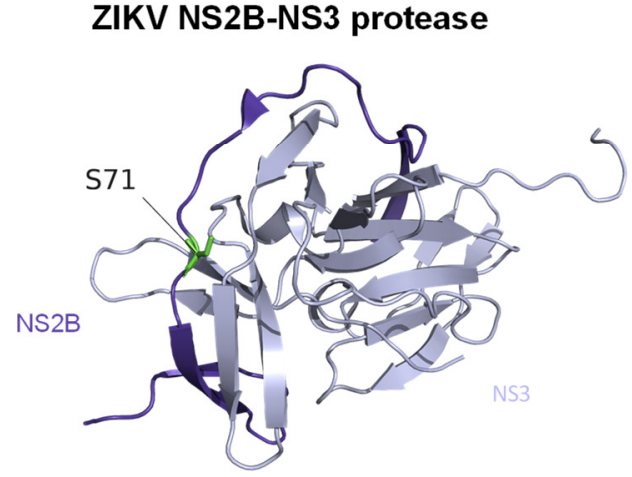

Epitope-rich ring

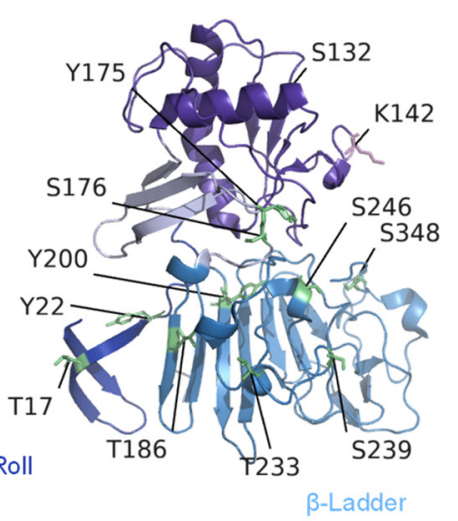

F

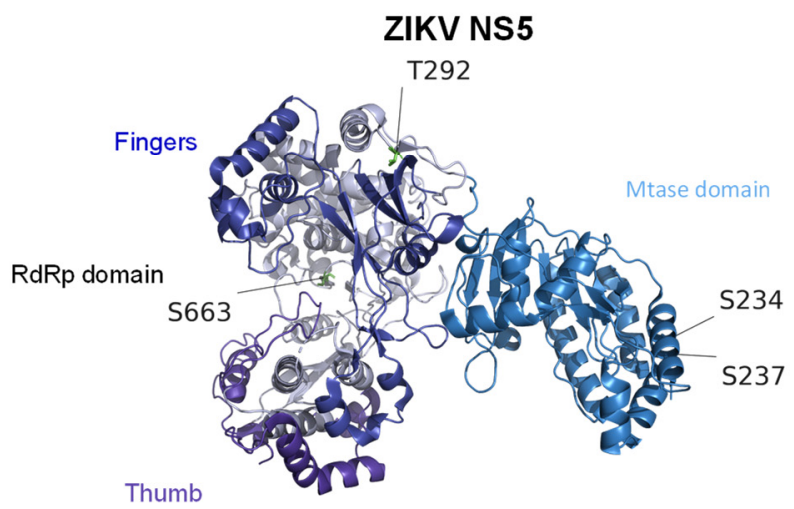


bioRxiv preprint doi: https://doi.org/10.1101/2021.11.24.469793; this version posted November 25, 2021. The copyright holder for this preprint (which was not certified by peer review) is the author/funder, who has granted bioRxiv a license to display the preprint in perpetuity. It is made available under aCC-BY-NC-ND 4.0 International license.

\section{Figure 3}

A

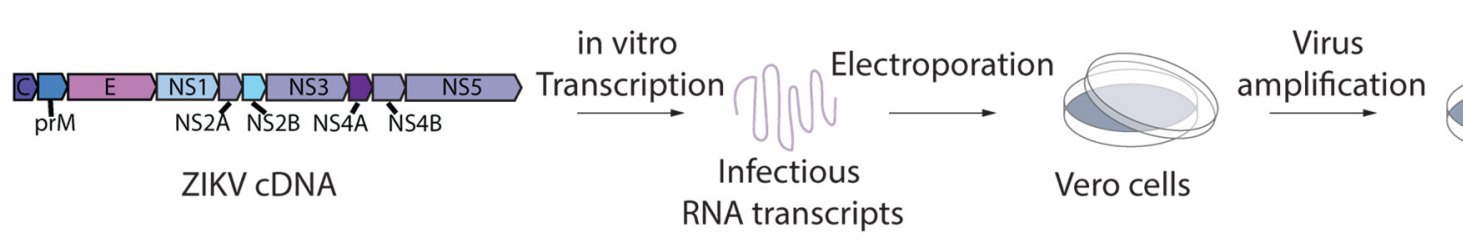

B

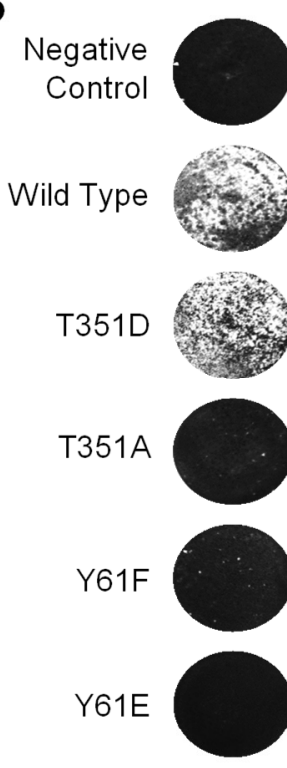

$10^{-1}$
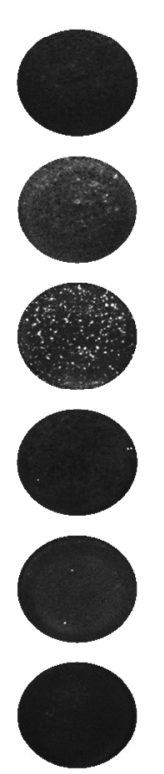

$10^{-2}$
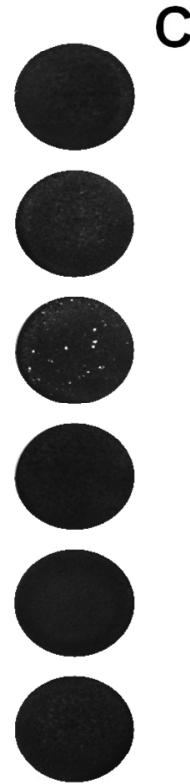

$10^{-3}$ RNA transcripts

C
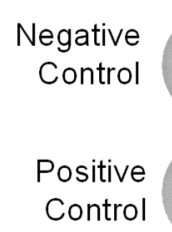

Y61F

Passage 1

\section{Y61E}

Passage 1

\section{Y61E}

Passage 2

Y61E / Y61V

Passage 3

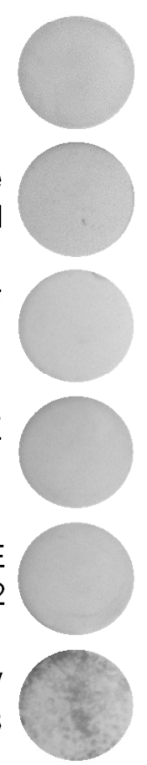

$10^{\circ}$
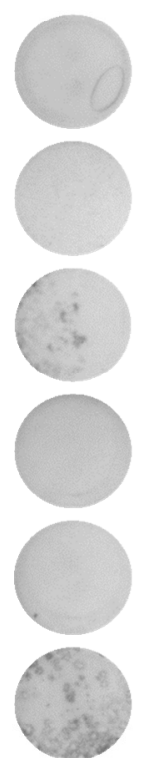

$10^{-1}$

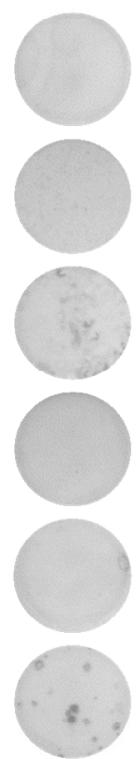

$10^{-2}$

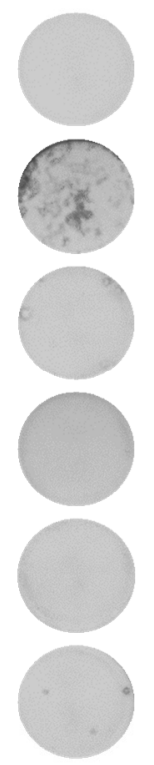

$10^{-3}$

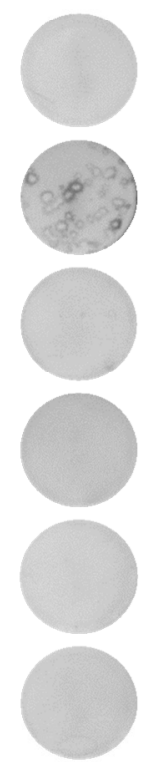

$10^{-4}$

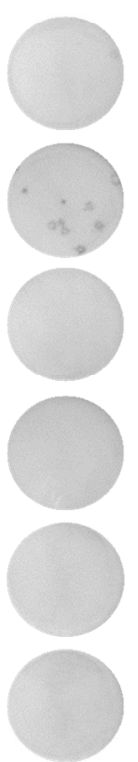

$10^{-5}$
D

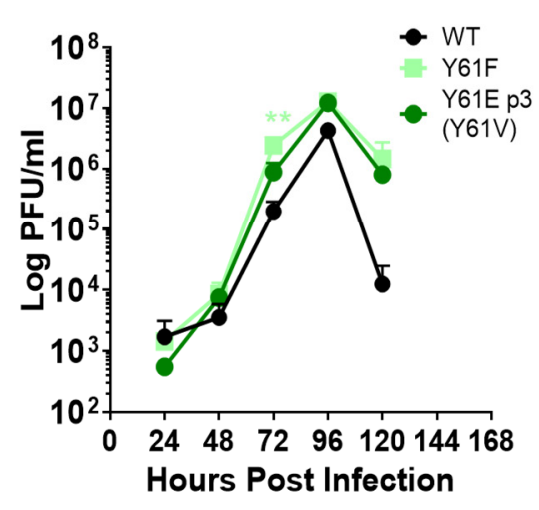

E

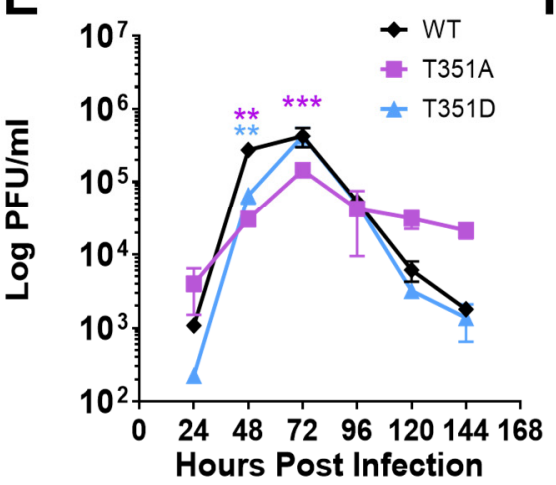

$\mathbf{F}$

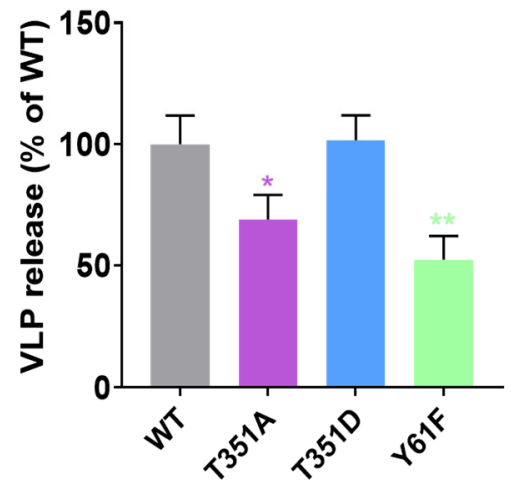


bioRxiv preprint doi: https://doi.org/10.1101/2021.11.24.469793; this version posted November 25, 2021. The copyright holder for this preprint (which was not certified by peer review) is the author/funder, who has granted bioRxiv a license to display the preprint in perpetuity. It is made available under aCC-BY-NC-ND 4.0 International license.

\section{Figure 4}

A

\section{ZIKV Protein Interacting Kinase Inhibitor}

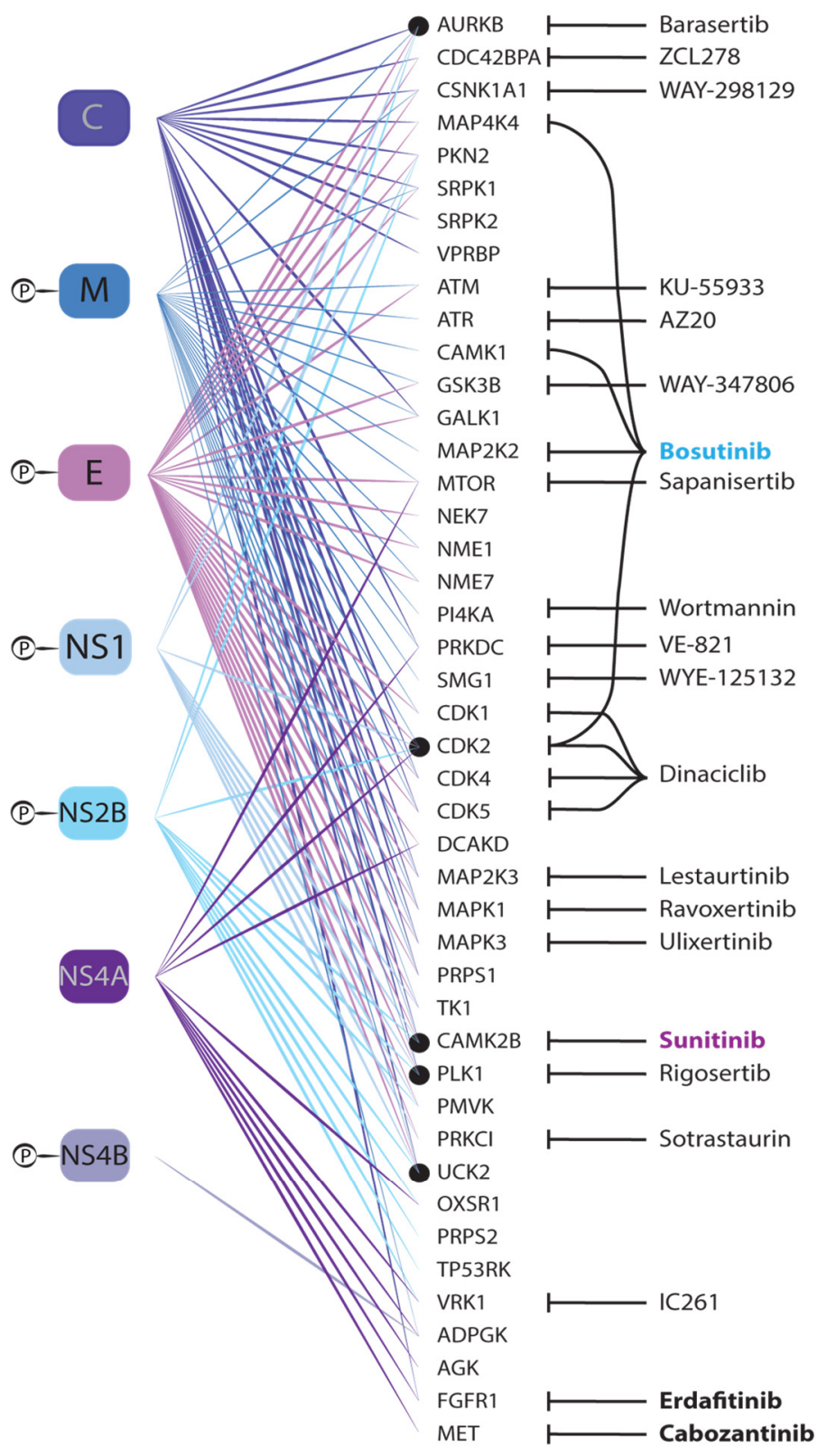

B
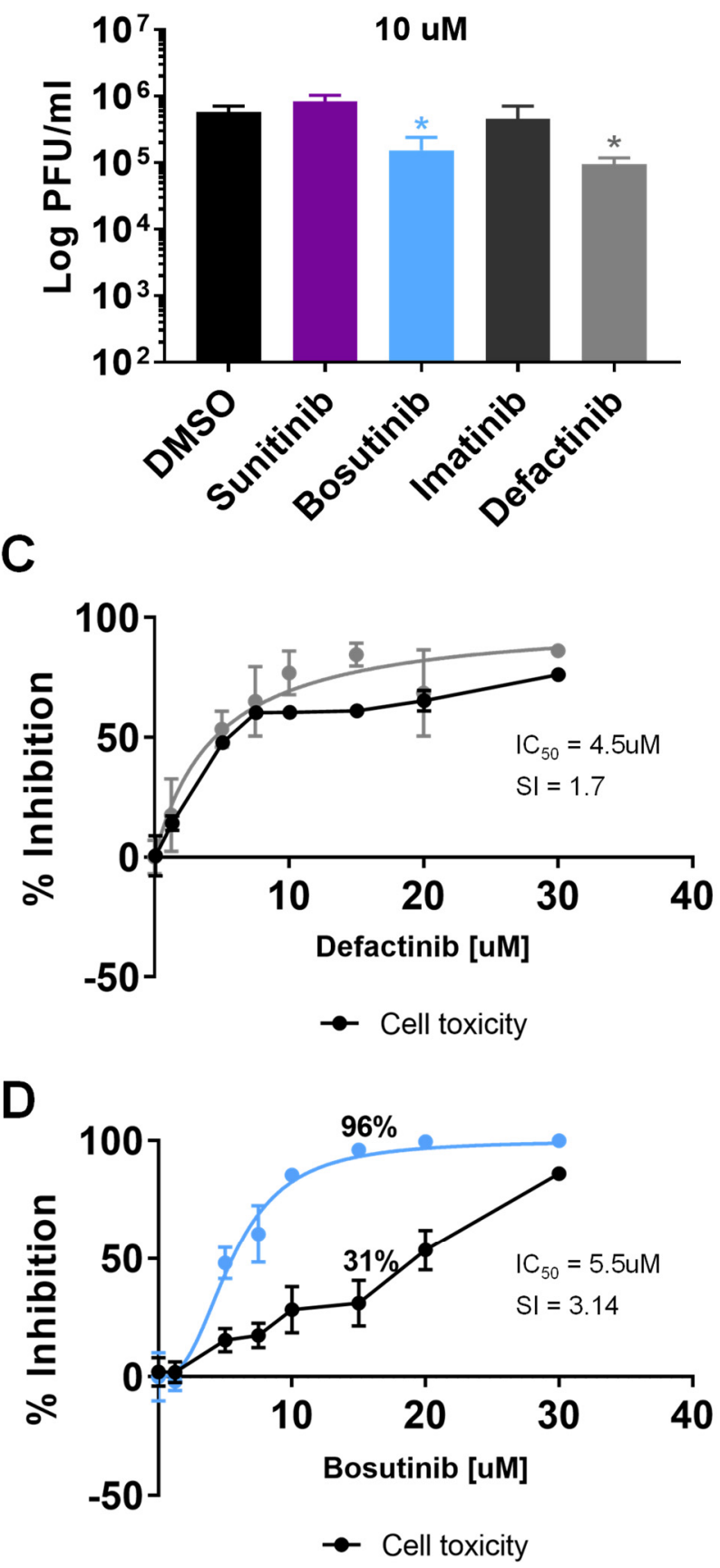
bioRxiv preprint doi: $\mathrm{https}$ //doi.org/10.1101/2021.11.24.469793: this version posted November 25, 2021. The copyright holder for this preprint (which was not certified by peer review) is the author/funder, who has granted bioRxiv a license to display the preprint in perpetuity. It is made available under aCC-BY-NC-ND 4.0 International license.

\section{Figure S1}
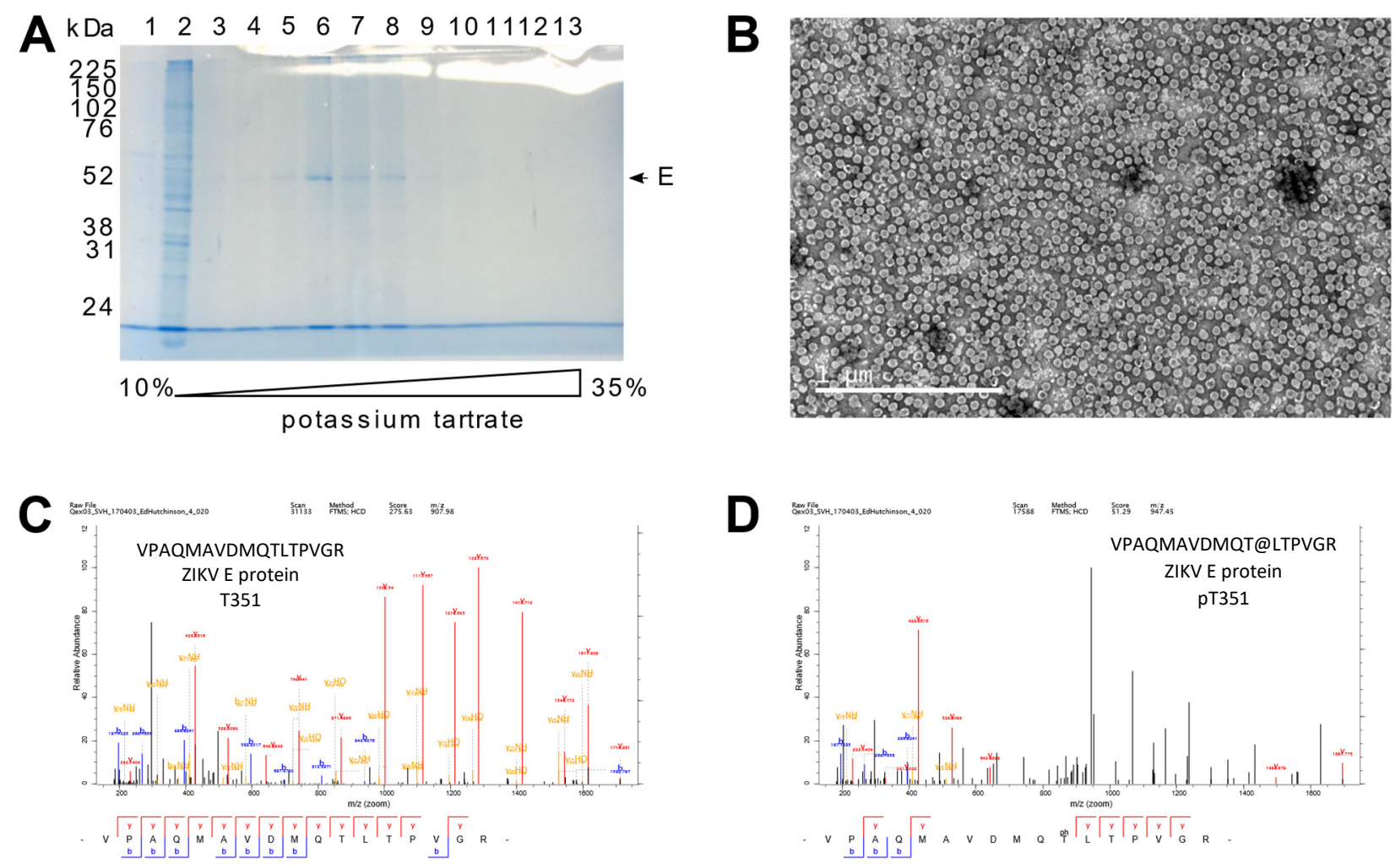
bioRxiv preprint doi: https://doi.org/10.1101/2021.11.24.469793; this version posted November 25,2021 . The copyright holder for this preprint

(which was not certified by peer review) is the author/funder, who has granted bioRxiv a license to display the preprint in perpetuity. It is made available under aCC-BY-NC-ND 4.0 International license.

\section{Figure S2}

DMSO
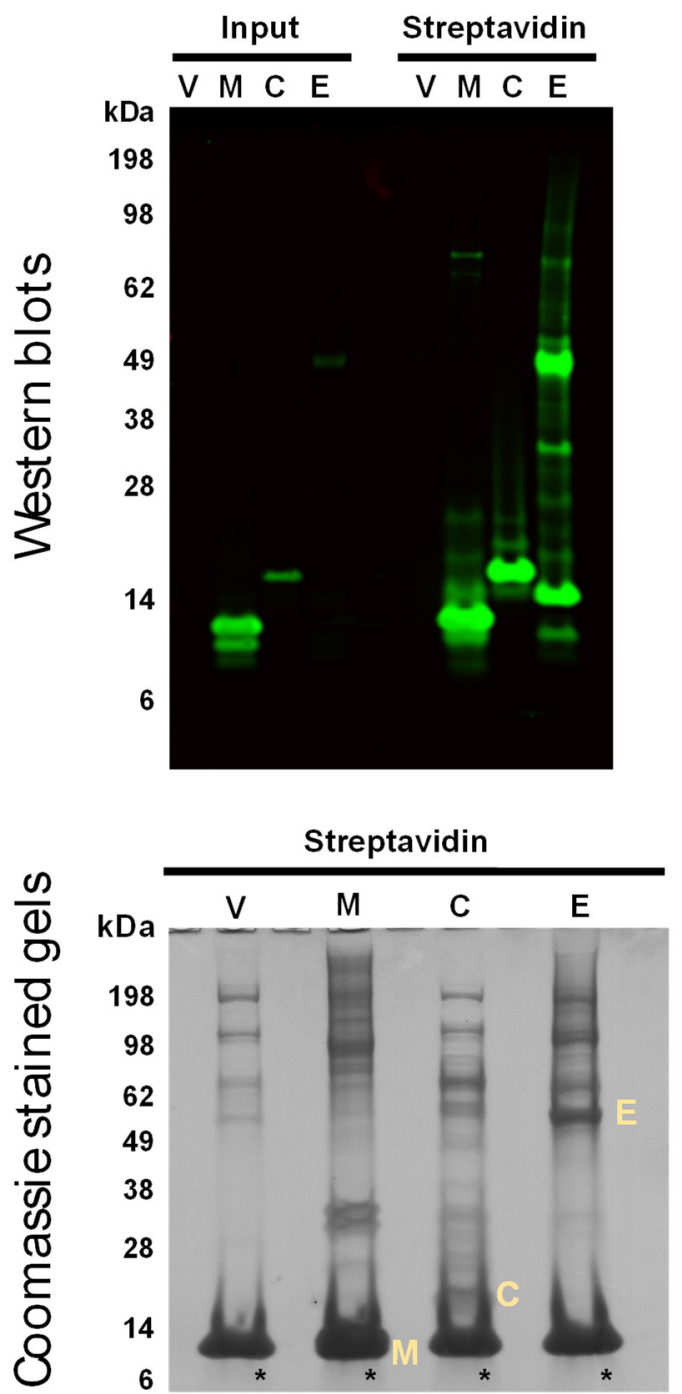

$\mathrm{H} 2 \mathrm{O} 2$

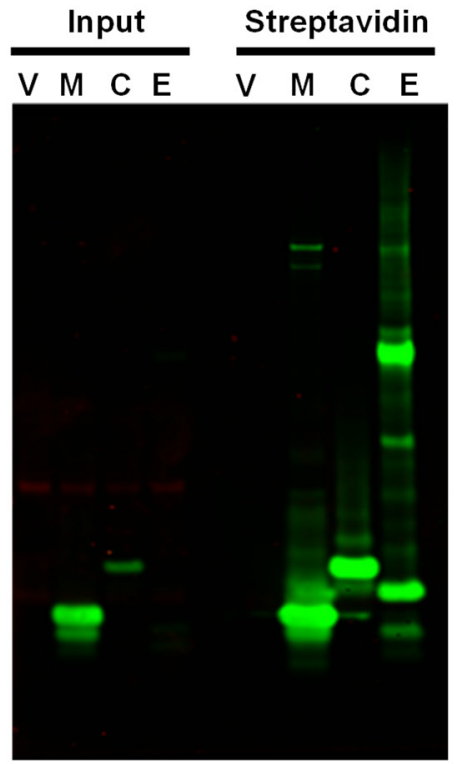

Streptavidin

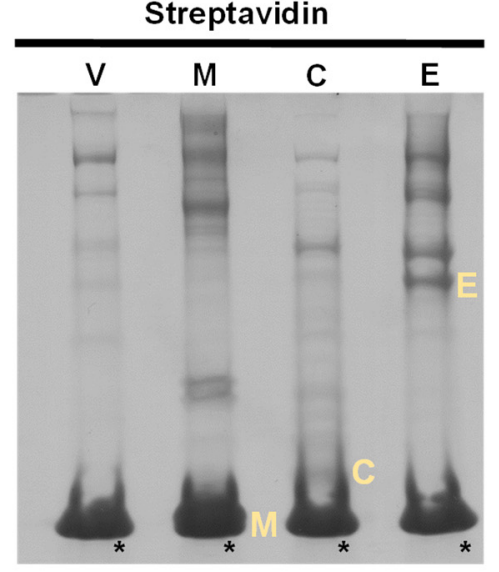

\section{Calyculin A}

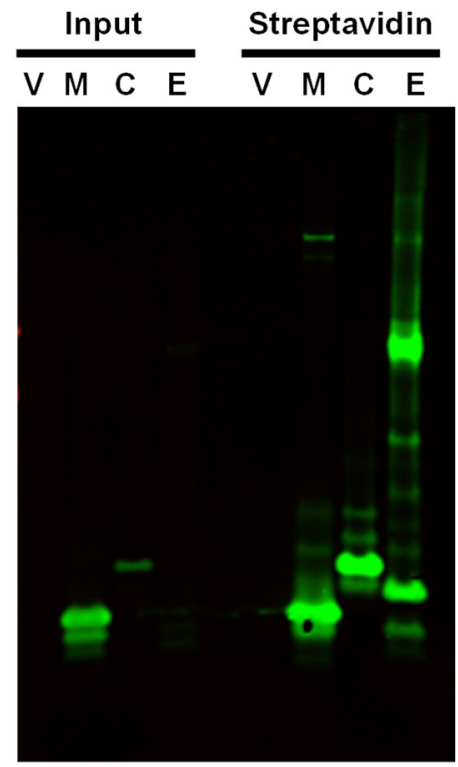

Streptavidin

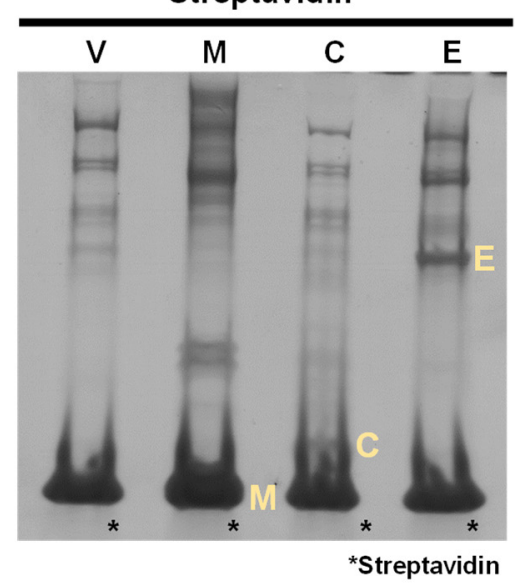




\section{Figure S3}

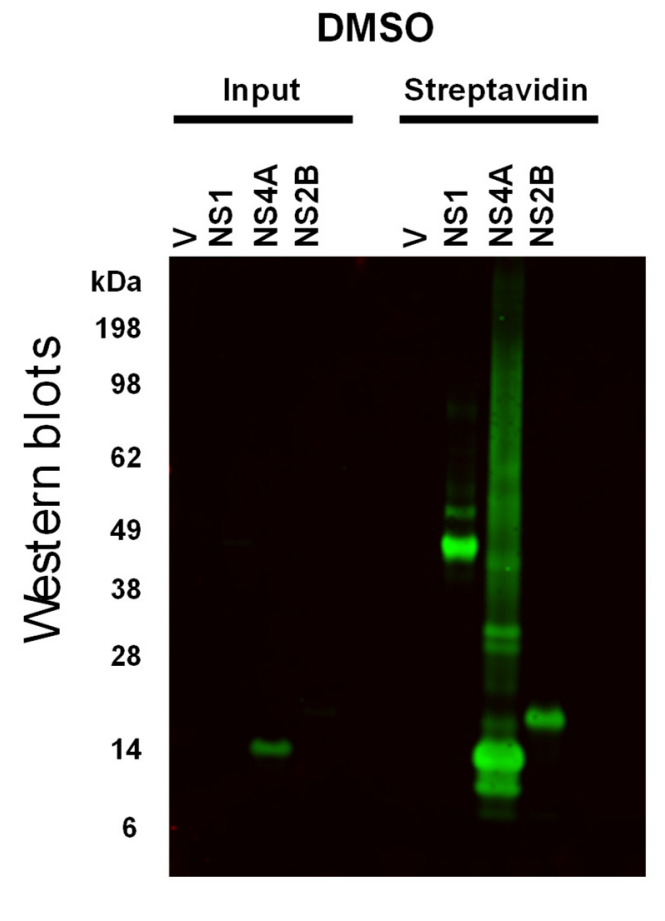

DMSO

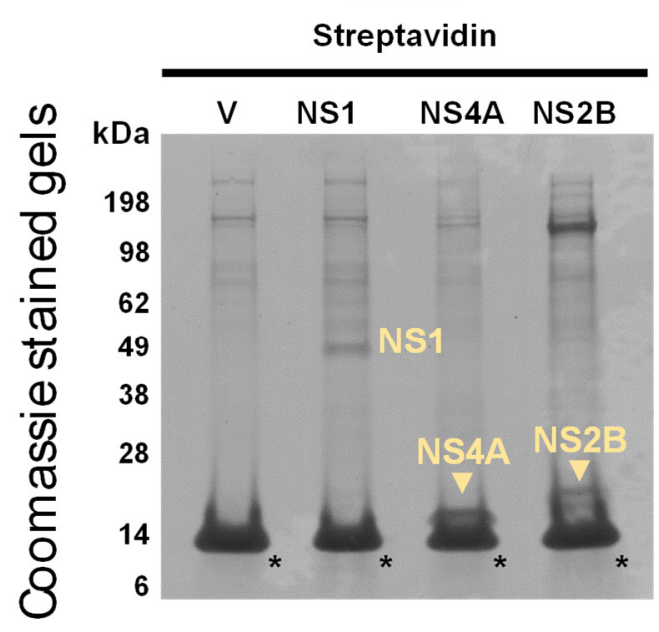

\section{$\mathrm{H} 2 \mathrm{O} 2$}

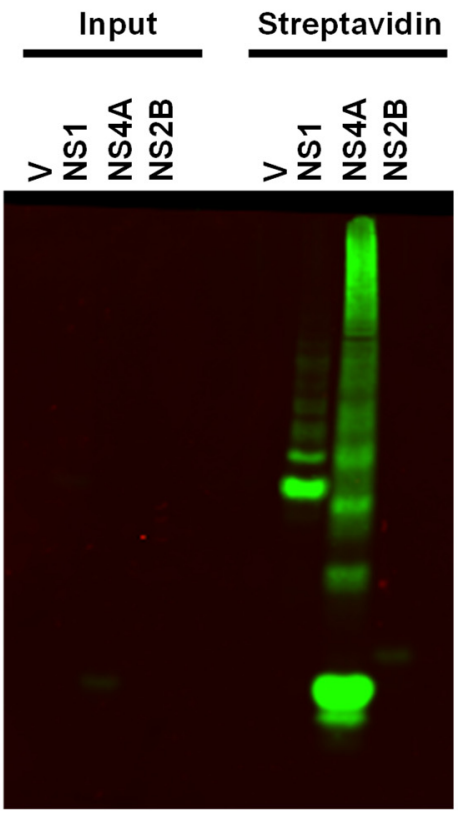

$\mathrm{H} 2 \mathrm{O} 2$

Streptavidin

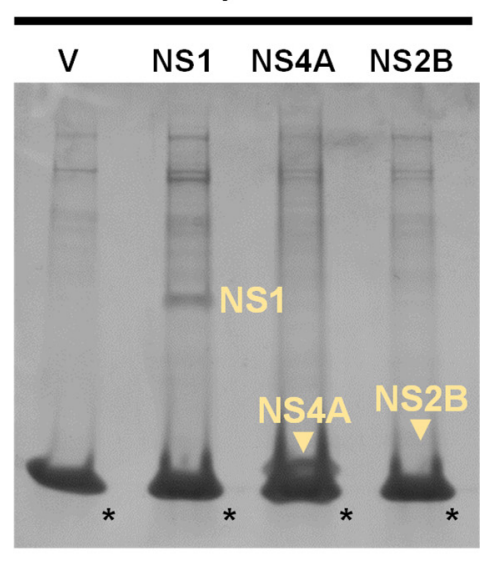

Calyculin A

Streptavidin

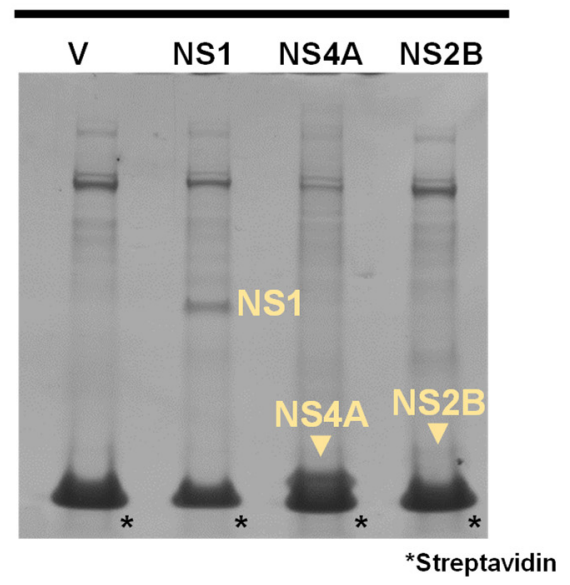




\section{Figure S4}
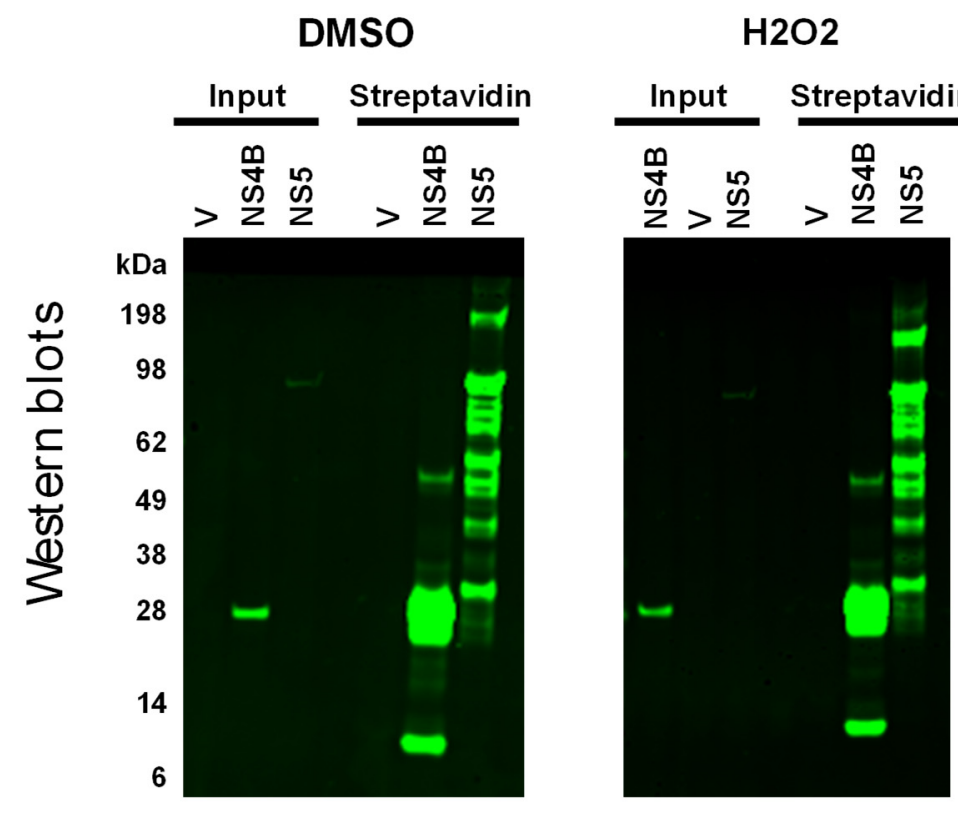

\section{Calyculin A}
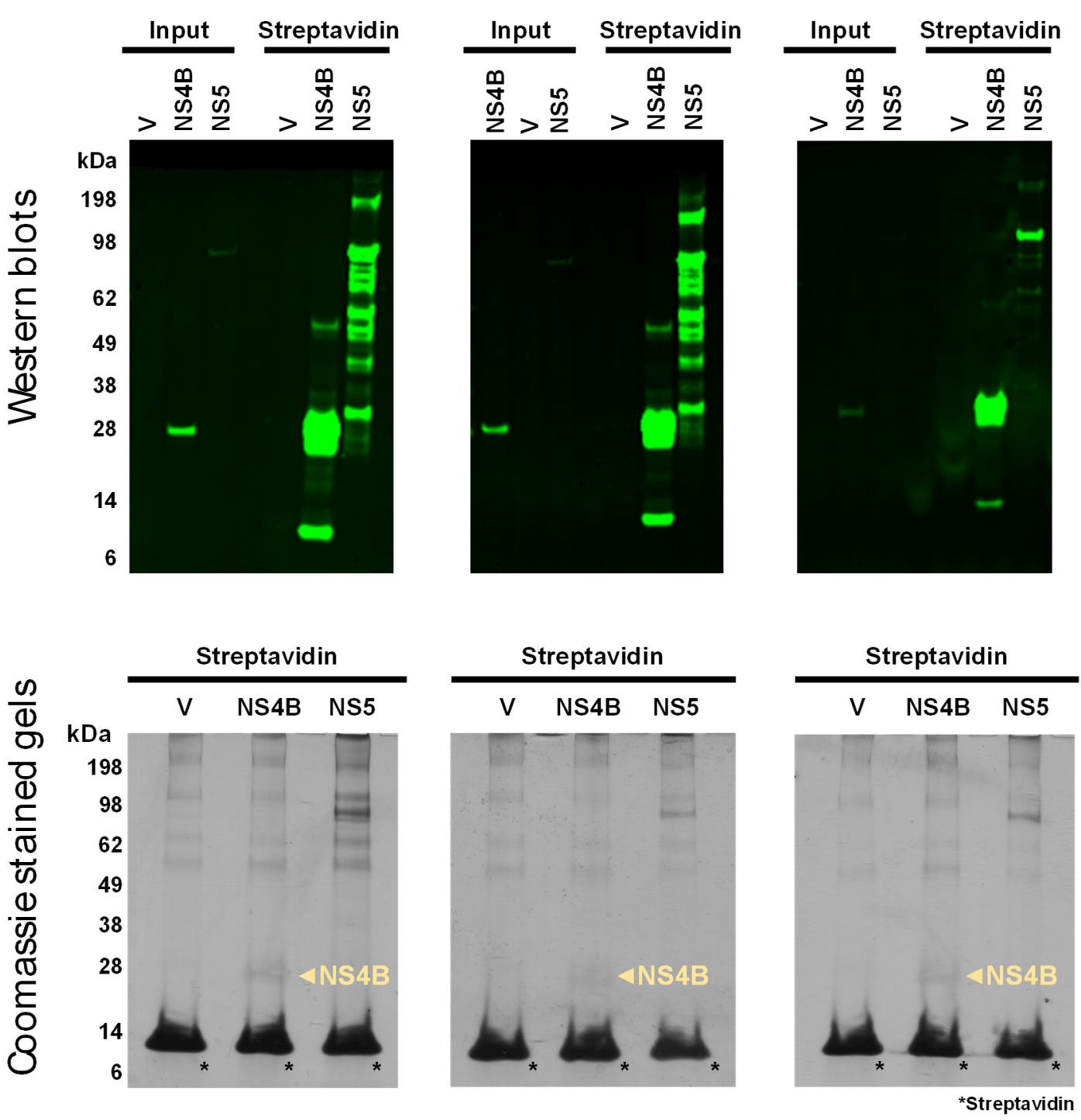


\section{Figure S5}

A

Positive Face - ZIKV E dimer

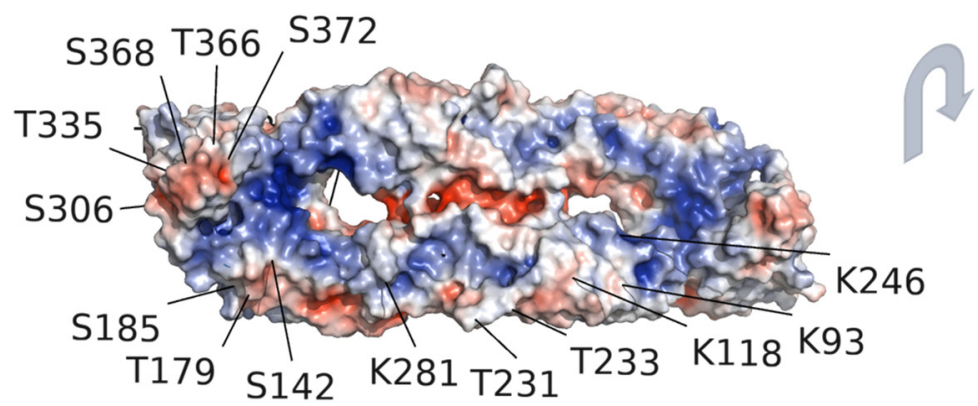

C

\section{Neutral Border - ZIKV E dimer}

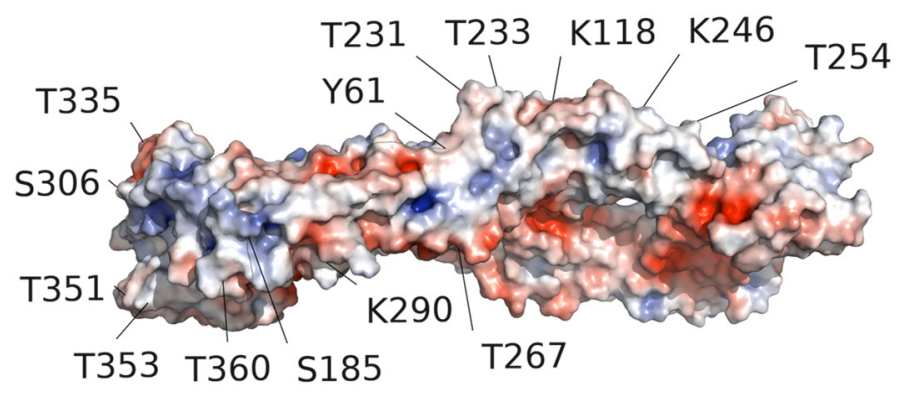

\section{Negative Face - ZIKV E dimer}

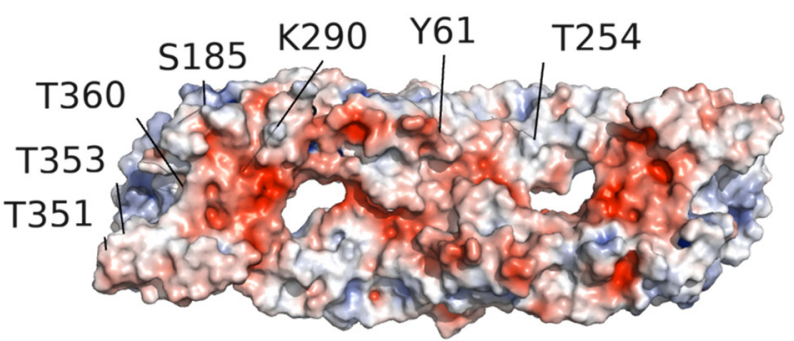




\section{Figure S6}

A

ZIKV M S16 and T18 magnified

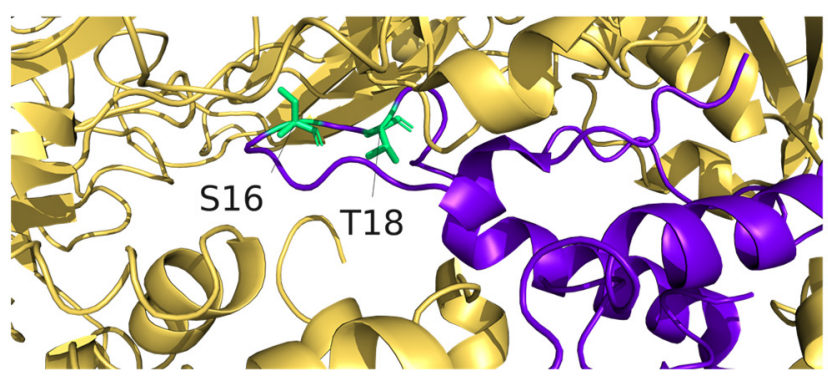

B ZIKV E Y61 magnified

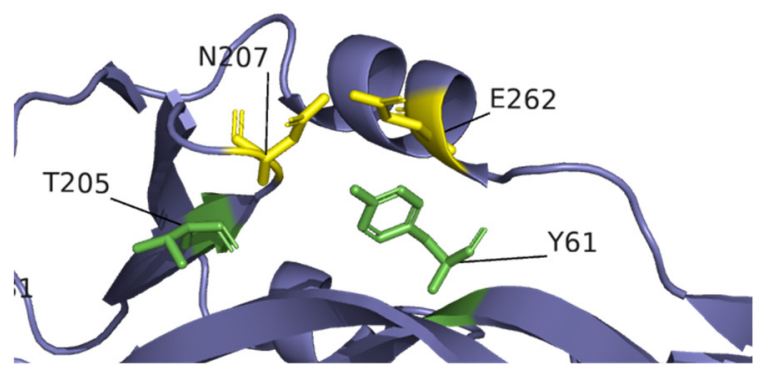


bioRxiv preprint doi: https://doi.org/10.1101/2021.11.24.469793; this version posted November 25, 2021. The copyright holder for this preprint (which was not certified by peer review) is the author/funder, who has granted bioRxiv a license to display the preprint in perpetuity. It is made available under aCC-BY-NC-ND 4.0 International license.

\section{Figure S7}

A

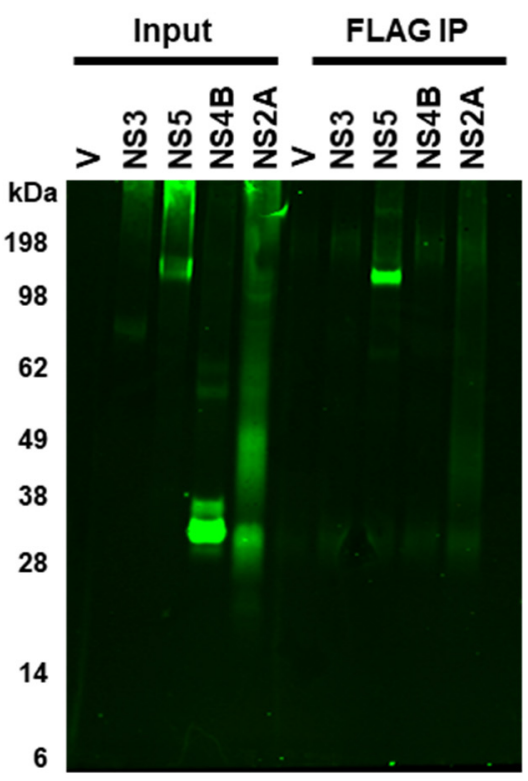

B

pOME SBP tagged
expression

expression
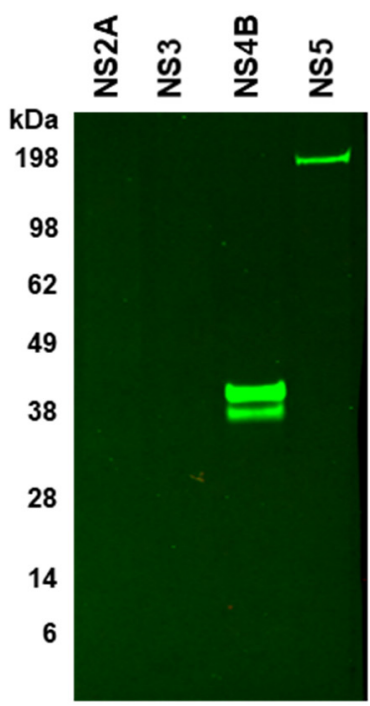